\title{
Conjugated Polymer Sorting of Semiconducting Carbon Nanotubes and their Electronic Applications
}

\author{
Huiliang Wang ${ }^{1}$, Zhenan $\mathrm{Bao}^{2}$ \\ ${ }^{1}$ Department of Materials Science and Engineering, \\ 2Department of Chemical Engineering, \\ Stanford University, California 94305, USA. \\ Corresponding Author: Zhenan Bao \\ Email: zbao@stanford.edu
}

Key words: Carbon nanotubes, semiconducting, conjugated polymer, sorting, electronics

\begin{abstract}
In the past decade, single-walled carbon nanotubes (SWNTs) have aroused great interest for electronic applications due to their extraordinary charge carrier mobility, mechanical flexibility, and solution processability. However, one of the key issues preventing the wide application of SWNTs in electronics is the need to separate semiconducting SWNTs from metallic SWNTs. Sorting semiconducting SWNTs using conjugated polymers is becoming a very promising SWNT sorting method due to its high-selectivity, high-yield and simplicity of execution. In this review, we summarized the parameters that can be used to tune the selectivity and sorting yield of semiconducting SWNTs, including polymer structure, solvent, polymer-to-SWNT ratio, sonication temperature and polymer molecular weight. We also reviewed the electronic applications enabled by these polymer-sorted semiconducting SWNTs inks such as transistors, logic gates, photodetectors, solar cells and 3D electronics.
\end{abstract}




\section{Introduction to Carbon Nanotubes}

Carbon nanotubes were first discovered in 1991 [1] and the first carbon nanotube transistors were not fabricated until 1998.[2, 3] Since then, intense research activities into carbon-nanotube-based electronics have been conducted. [4-7] Single-walled carbon nanotubes (SWNTs) are attracted for electronic applications because of their extraordinary charge carrier mobilities, [7-9] mechanical flexible/stretchability,[10-15] and solution processiblity.[16-19] In particular, semiconducting SWNTs have emerged as a promising class of materials for a variety of electronic applications, such as field-effect transistors, [7, 20-24] optoelectronic devices,[25-27] chemical and biological sensors,[28-31] logic circuits,[20, 21, 32] electronic skins,[20,33] and computers.[34]

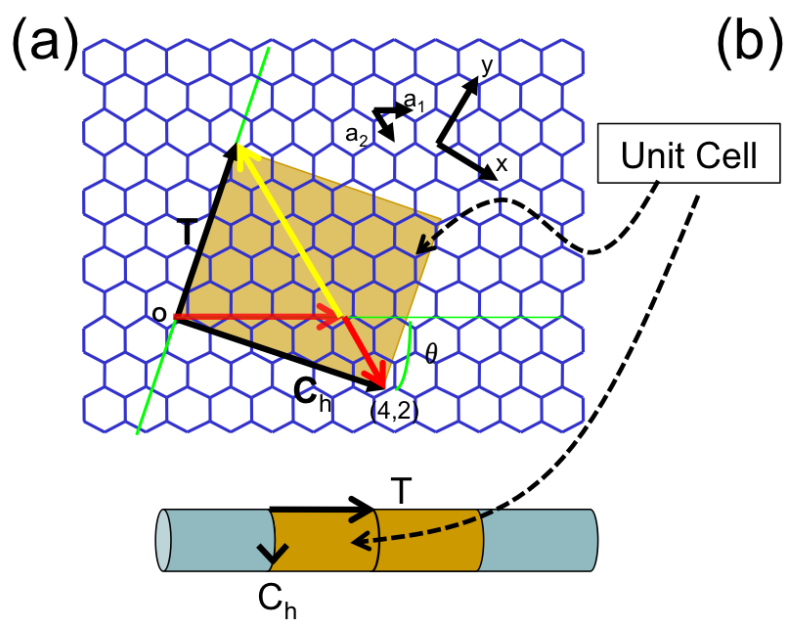

(b)

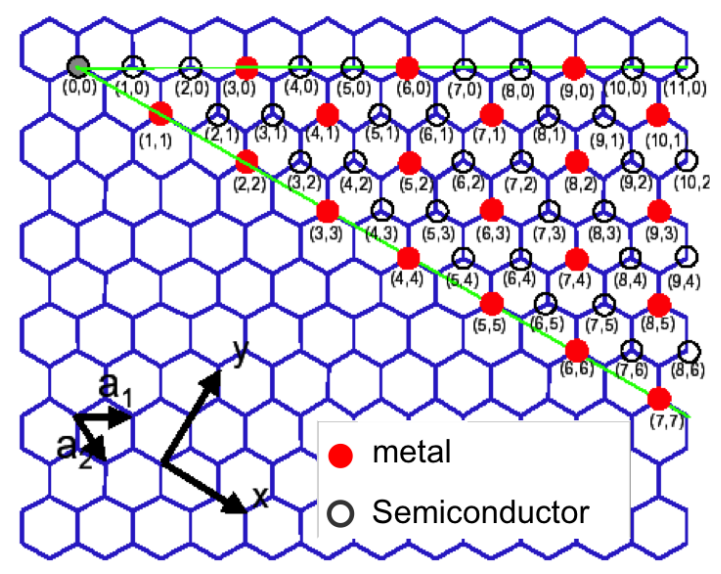

Figure 1 Graphic representation showing the structure of SWNTs. (a) Schematic illustration of the structures of a $(4,2)$ SWNT with lattice chiral vector $\mathrm{C}_{\mathrm{h}}$ and tube axis T. (b) Graphene sheet map showing the chirality of various metallic and semiconducting SWNTs with $\mathrm{C}_{\mathrm{h}}$ from $(0,0)$ to the shown SWNT chirality.

The electronic properties of SWNTs are determined by their structures, which can be conceptualized as a single-layer graphene sheet rolled into a cylinder along a lattice chiral vector $\left(C_{h}\right)$ (Figure 1a), described by

$C_{h}=n \mathrm{a}_{1}+m \mathrm{a}_{2}=(n, m)$

where $\mathrm{a}_{1}$ and $\mathrm{a}_{2}$ are the unit vectors of the graphene and $n$ and $m$ are a pair of integers describing the 
chirality of the SWNT. A SWNT with a chirality of $(4,2)$ has a chiral vector oriented in the $\mathrm{a}_{1}$ direction for 4 units and in the $a_{2}$ direction for 2 units (Figure 1a). If $m=0$, the SWNTs are called zigzag SWNTs and if $n=m$, the SWNTs are called armchair SWNTs. For most chiralities of SWNTs (other than zigzag or armchair SWNTs), there are two optical isomers for each chirality: left-handed twist or righthanded twist. Both handed isomers have the same chiral vector $(n, m)$ but they can not be superimposed on each other.

The diameter $(d)$ and chiral angle $(\theta)$ can be calculated from the indices of $n$ and $m$ using the following equation:

$$
\begin{aligned}
& d=\frac{a}{\sqrt{n^{2}+m^{2}+n m}} \\
& \cos =\frac{2 n+m}{2 \sqrt{n^{2}+m^{2}+n m}}
\end{aligned}
$$

The electronic properties of SWNTs are determined by their chirality $(n, m)$ : when $n-m$ is a multiple of 3, the SWNT is metallic; when $n-m$ is not a multiple of 3, the SWNT is semiconducting (Figure 1b). Approximately one third of SWNTs are metallic, and the remainder are semiconducting. For semiconducting SWNTs, the band gap is inversely proportional to their diameters, in accordance with a simple tight binding model:[7]

$$
E_{g}=\left(2 R_{C C} / d_{C N T}\right)
$$

where is the hopping matrix element $(\sim 3 \mathrm{eV}), R_{C-C}$ is the $\mathrm{C}-\mathrm{C}$ bond length, and $d_{C N T}$ is the SWNT diameter.

Different synthesis methods can produce SWNTs with different diameters. SWNT synthesis methods for mass production include the arc discharge method,[1] laser ablation, [35] and chemical vapor deposition (CVD). [36-38] The diameters of the SWNTs produced by these methods are summarized in Table 1. Unfortunately, these scalable methods can produce only mixtures of metallic SWNTs and semiconducting SWNTs. Because pure semiconducting SWNTs are required for a range of electronic 
applications, the ability to obtain pure semiconducting SWNTs from as-synthesized SWNT mixtures is very important.

\begin{tabular}{|c|c|c|c|}
\hline \multicolumn{2}{|c|}{ Synthesis method } & Description of the method & Diameter \\
\hline \multicolumn{2}{|l|}{ Arc discharge[1] } & $\begin{array}{l}\text { Application of a voltage between two } \\
\text { graphite electrodes to produce an arc; } \\
\text { SWNTs are deposited on the electrodes. }\end{array}$ & $1.2 \sim 1.7 \mathrm{~nm}$ \\
\hline \multicolumn{2}{|c|}{ Laser ablation [35] } & $\begin{array}{l}\text { Application of laser pulses to graphite } \\
\text { heated in a tube furnace to produce } \\
\text { SWNTs. }\end{array}$ & $1.0 \sim 1.4 \mathrm{~nm}$ \\
\hline \multirow{2}{*}{$\begin{array}{l}\text { Chemical vapor } \\
\text { deposition } \\
\text { (CVD)[36] }\end{array}$} & $\begin{array}{l}\text { High-pressure CO } \\
\text { (HiPco)[37] }\end{array}$ & $\begin{array}{l}\text { Decomposition of high-pressure CO at } \\
\text { high temperatures to nucleate SWNTs. }\end{array}$ & $0.8 \sim 1.1 \mathrm{~nm}$ \\
\hline & $\begin{array}{l}\text { CO disproportionation } \\
\text { on Co-Mo } \\
\text { catalysts[38] } \\
\text { (CoMoCAT) }\end{array}$ & $\begin{array}{l}\text { Decomposition of CO gas at high } \\
\text { temperatures with Co and Mo as catalysts } \\
\text { to produce SWNTs. }\end{array}$ & $0.7 \sim 0.9 \mathrm{~nm}$ \\
\hline
\end{tabular}

Table 1 Summary of synthesis methods, including their descriptions and the diameter ranges of the SWNTs they produce commercially.

The selective dispersion of SWNTs has been a key research topic over the past decade.[39-43]

Methods for separating semiconducting SWNTs include the sorting of SWNTs in solution,[44-49] the removal of metallic SWNTs after growth,[50-52] interactions via surface functional groups[53, 54] and chemical reactions with SWNTs. $[55,56]$ The solution-based sorting of semiconducting SWNTs via non-covalent functionalization has been shown to be an excellent method for selecting pure semiconducting SWNTs without altering their electrical properties (Figure 2). These solution-based sorting methods include the wrapping of SWNTs with DNA molecules (Figure 2a),[45, 57] density gradient ultracentrifugation (Figure 2b),[46, 58] gel chromatography (Figure 2c),[47, 59] partition separation[60, 61] and the wrapping of SWNTs with a conjugated polymer (Figure 2d).[48, 49, 62] Several methods are even capable of sorting single-chirality SWNTs. [57-59, 61] Among these 
methods, wrapping semiconducting SWNTs with conjugated polymers is one of the simplest, most selective and most scalable methods for the large-scale sorting of SWNTs.[48, 49, 63, 64]
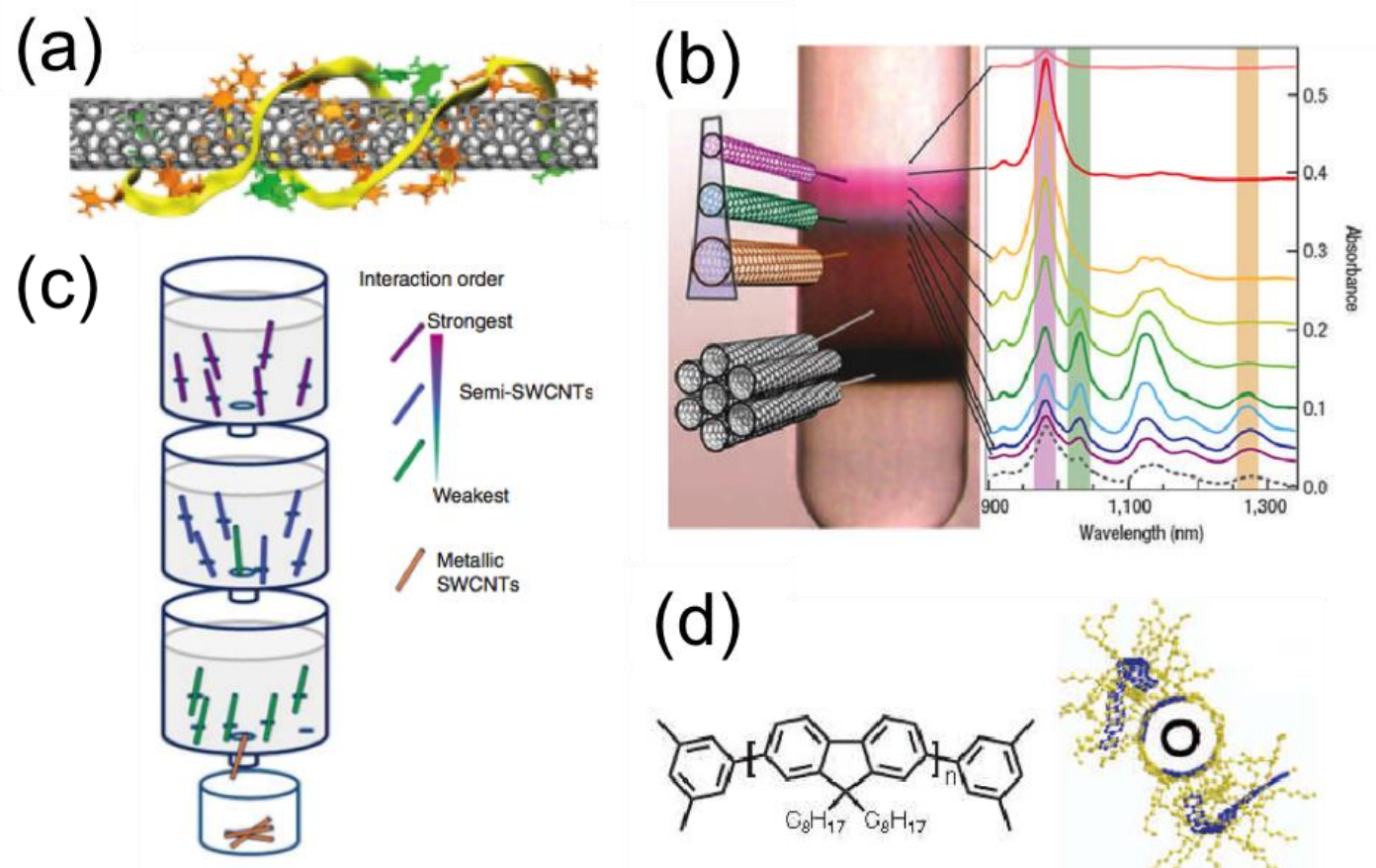

Figure 2 Different solution-sorting methods for semiconducting SWNTs. (a) DNA wrapping, [57](b) Density gradient ultracentrifuge, [46] (c) Gel chromatography, [59](d) Conjugated polymer wrapping. [48] Reprinted with permission from ref. 57, 46, 59 and 48. Copyright 2009 Nature Publishing Group, 2006 Nature Publishing Group, 2011 Nature Publishing Group, 2007 Nature Publishing Group.

\section{Sorting semiconducting SWNTs using conjugated polymers}

Conjugated polymers, with extensive pi-conjugated structures, have been used in a variety of applications such as light-emitting diodes,[65-67] organic solar cells[68-70], organic transistors[7174] and chemical/biological sensors. [75-77] These polymers have also been reported to interact with SWNTs through non-covalent pi-pi interactions.[78, 79] However, they have been known to selectively disperse semiconducting SWNTs, as reported by Nish et al., only since 2007. [48] The polymer sorting process only involves (1) sonication of SWNTs and polymers mixtures in organic solvents for around 30 minutes to disperse SWNTs, (2) centrifuge polymer wrapped SWNTs solution for 1 2 hours to sediment the SWNT aggregates / metallic SWNTs and (3) collect the semiconducting SWNT supernatants, which are ready for use. For the application of sorted 
semiconducting SWNTs in electronic applications, the sorting yield and selectivity are two of the most important criteria: the sorting yield represents the amount of semiconducting SWNTs produced from the original raw samples, whereas the purity indicates the percentage of semiconducting SWNTs in the final SWNT mixture. The ability to sort out specific diameters and chirality of SWNTs is most desirable for ensuring uniform band gaps. In this section, we will begin by discussing the sorting of different types SWNTs (CoMoCAT, HiPco, laser ablation and arc discharge) by various polymer structures. Then, the effects of the solvent, the polymer/SWNT ratio, the sonication temperature and the molecular weight of the polymers are discussed. Finally, a general mechanism is proposed for explaining the selective dispersion of semiconducting SWNTs, consistent with the observation of various experimental results.

\subsection{Effects of polymer structures on various types of SWNTs}

\subsubsection{CoMoCAT SWNTs}

CoMoCAT SWNTs have the smallest diameter among all mass-produced SWNTs. Nish et al. reported the sorting of semiconducting CoMoCAT SWNTs using PFO (P1, Figure 3a) in toluene. [48] CoMoCAT SWNTs with a primary chirality of $(7,5)$ were selectively dispersed (Figure $\mathbf{3 b}$, Table 2 ). The selectivity of this method is attributed to the formation of self-assembled intermolecular structures between SWNTs of certain diameters and the polymers, as indicated by molecular dynamics (MD) simulations. These simulations also demonstrated that the number of polymers wrapped on the SWNTs increase from two to four as the diameter of the SWNTs increases.[48] When PFO-BPy (P2, Figure 3a) is used as the sorting polymer, the purity of sorted single-chirality $(6,5)$ semiconducting SWNTs can be as high as 97\% (Table 2).[80] Through incorporation of chiral moieties into the conjugated polymers, sorting of single-handed semiconducting SWNTs have also been achieved, as confirmed by circular dichroism (CD) spectroscopy.[81, 82] 
(a)
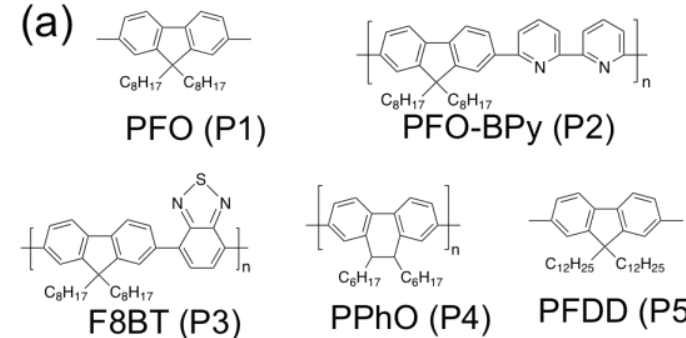

$\mathrm{PPhO}(\mathrm{P} 4)$

PFDD (P5)
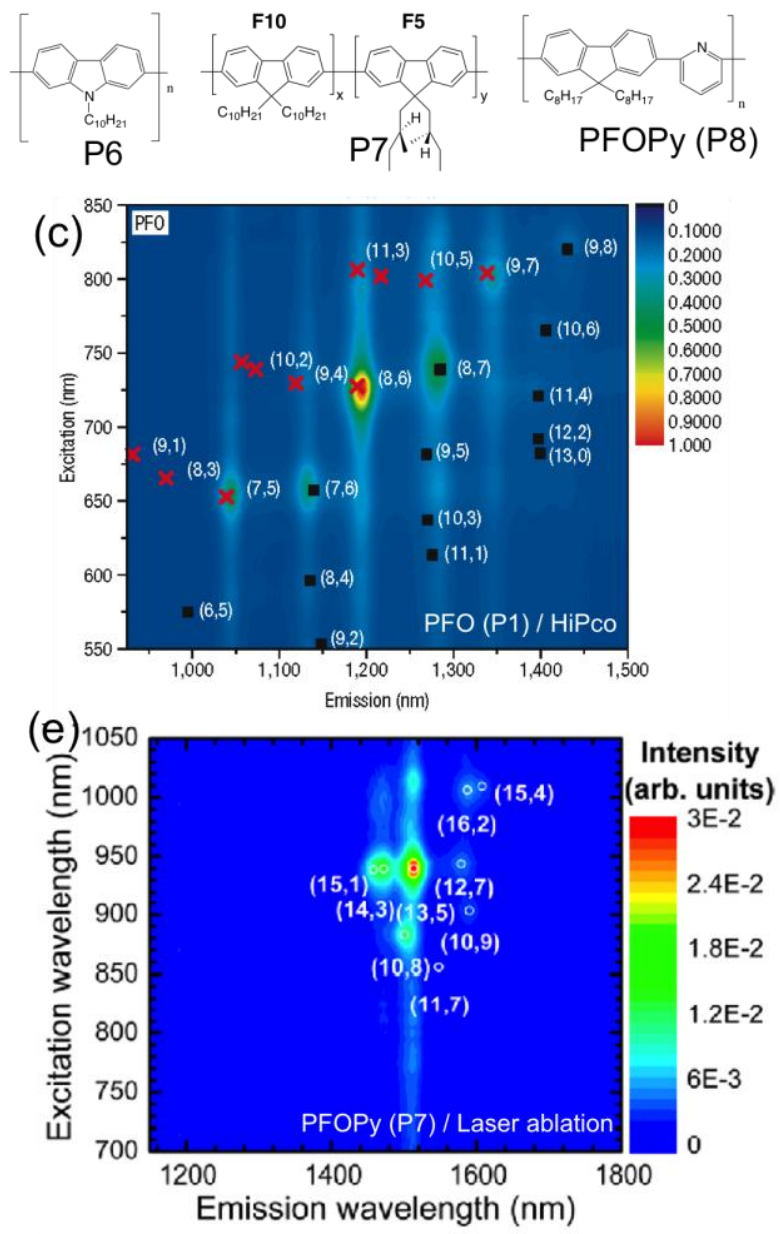
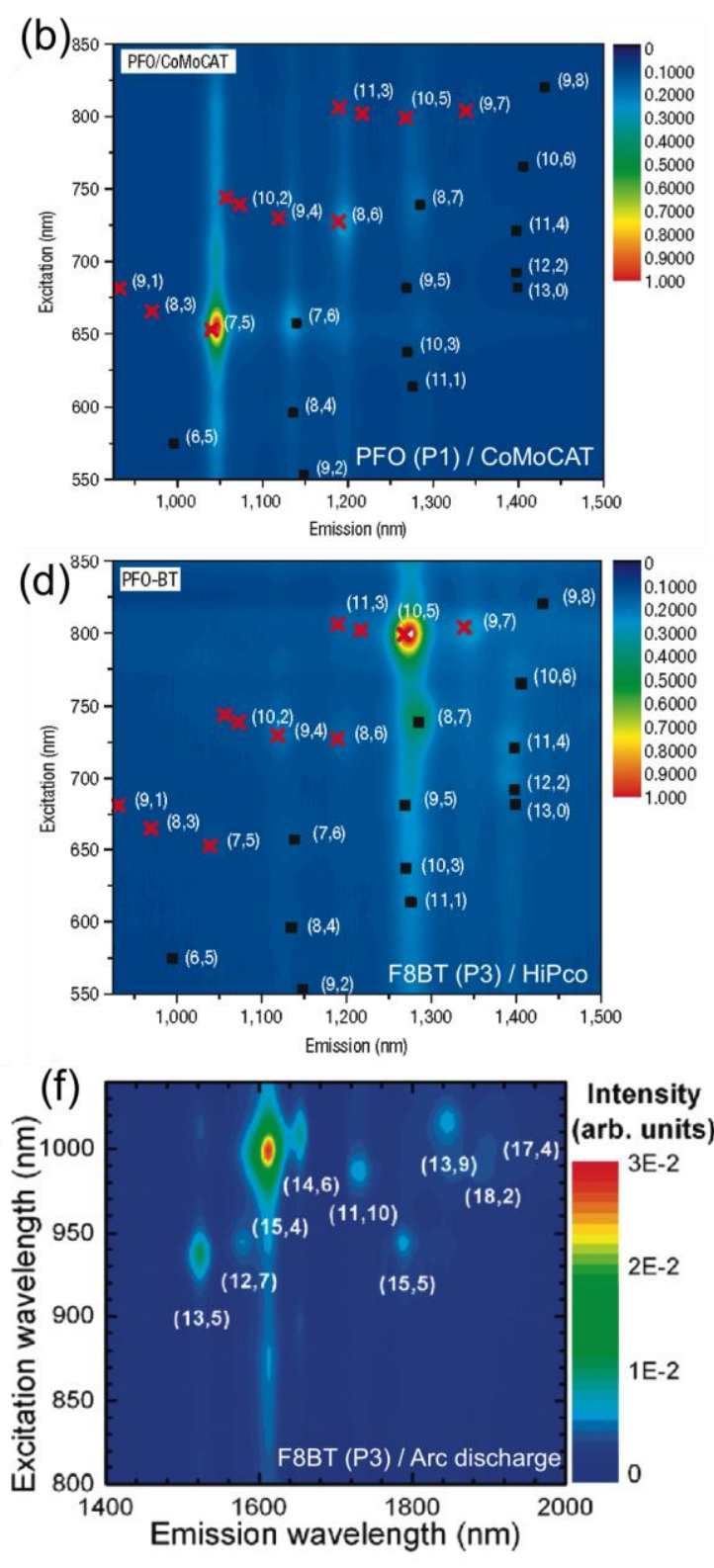

Figure 3 Conjugated polymers for sorting narrow chirality distribution of SWNTs. (a) Chemical structures of the highly selective conjugated polymers. Photoluminescence excitation maps for (b) Sorted CoMoCAT SWNTs by PFO,[48] (c) Sorted HiPco SWNTs by PFO,[48] (d) Sorted HiPco SWNTs by F8BT,[48] (e) Sorted Laser ablation SWNTs by PFOPy,[83] (f) Sorted Arc discharge SWNTs by F8BT.[84] Reprinted with permission from ref. 48, 80, 81. Copyright 2007 Nature Publishing Group, Copyright 2012 American Chemical Society, Copyright 2011 American Chemical Society.

We applied regioregular polythiophene (rr-P3ATs, Figure 4a) to disperse semiconducting CoMoCAT SWNTs with a high yield. We found that by increasing the side-chain length of our polythiophenes, 
we could significantly increase the sorting yield of the CoMoCAT SWNTs (Figure 4b). [64] MD simulations in explicit toluene molecules demonstrated that the increased sorting yield is attributable to the increased surface contact area between the SWNTs and the longer side-chain polymers (Figure 4c). In comparison to unsorted CoMoCAT SWNTs, the sorting process yields smaller-diameter, larger-band-gap SWNTs, which are ideal for use as active layers in solar cell applications. [64]

\begin{tabular}{|l|l|l|l|l|l|}
\hline Polymer structure & SWNT type & $\begin{array}{l}\text { Sorted primary } \\
\text { chirality }\end{array}$ & $\begin{array}{l}\text { Diameter } \\
\text { (nm) }\end{array}$ & $\begin{array}{l}\text { Chiral } \\
\text { angle }\end{array}$ & Solvent \\
\hline \multirow{3}{*}{ PF0 (P1) } & CoMoCAT[48, 85] & $\mathbf{( 7 , 5 )}$ & 0.82 & $24.5^{\circ}$ & Toluene \\
\cline { 2 - 6 } & HiPco[48, 85] & $\mathbf{( 8 , 6 )}$ & 0.95 & $25.3^{\circ}$ & Toluene \\
\cline { 2 - 6 } & Laser ablation[86] & $\mathbf{( 9 , 7 )}$ & 1.09 & $25.9^{\circ}$ & Toluene \\
\hline PF0-BPy (P2) & CoMoCAT[80] & $\mathbf{( 6 , 5 )}$ & 0.76 & $27.0^{\circ}$ & Toluene \\
\hline \multirow{3}{*}{ F8BT (P3) } & HiPco[48] & $\mathbf{( 1 0 , 5 )}$ & 1.05 & $19.1^{\circ}$ & Toluene \\
\cline { 2 - 6 } & HiPco[87] & $\mathbf{( 9 , 4 )}$ & 0.90 & $17.5^{\circ}$ & o-Xylene \\
\cline { 2 - 6 } & Arc discharge[84] & $\mathbf{( 1 5 , 4 )}$ & 1.36 & $11.5^{\circ}$ & Toluene \\
\hline PPh0 (P4) & HiPco[88] & $\mathbf{( 8 , 7 )}$ & 1.03 & $27.8^{\circ}$ & Toluene \\
\hline PFDD (P5) & HiPco[89] & $\mathbf{( 7 , 6 )}$ & 0.88 & $27.5^{\circ}$ & Toluene \\
\hline P6 & HiPco[90] & & & $\theta<20^{\circ}$ & Toluene \\
\hline P7 x:y=100:0 & HiPco[91] & & & $\theta>24^{\circ}$ & Toluene \\
\hline P7 x:y=15:85 & HiPco[91] & $\mathbf{( 1 0 , 3 )}$ & 0.94 & $12.7^{\circ}$ & Toluene \\
\hline PF0Py (P8) & Laser ablation[83] & $\mathbf{( 1 3 , 5 )}$ & 1.26 & $15.6^{\circ}$ & Toluene \\
\hline
\end{tabular}

Table 2 List of highly selective conjugated polymers and the SWNT chirality, diameter and chiral angle that they most strongly enrich.

\subsubsection{HiPco SWNTs}

Conjugated polymers have also been extensively investigated for the sorting of HiPco SWNTs. [48, $49,85,90-109]$ Several of them can sort very specific chirality of SWNTs. Nish et al. [48] and Chen et al.[85] first observed that PFO (P1, Figure 3a) enriches small-diameter $(8,6)$ SWNTs, whereas F8BT (P3, Figure 3a) enriches larger-diameter (10,5) SWNTs (Figure 3c,d, Table 2). MD simulations indicate that the PFO wrapping of $(8,6)$ SWNTs is more stable than that of other SWNT chiralities, consistent with the experimental results. [92] PPhO (P4, Figure 3a), with a slight modification of the PFO backbone, can enrich (8,7) SWNTs (Table 2). [93] Similarly, PFDD (P5, Figure 3a), with a longer side-chain than that of PFO, enables the selective dispersion of primarily $(7,6)$ SWNTs (Table 2).[89] While PFO derivatives selectively disperse HiPco SWNTs with a chiral angle $\theta \geq 20^{\circ}$, Lemasson et al. 
found that polycarbazoles (P6, Figure 3a) selectively disperse SWNTs with a chiral angle $\theta \leq 20^{\circ}$

(Table 2).[90] In an attempt to identify any trends in the effects of the polymer structure on sorting, Ozawa et al. systematically varied the ratio of the standard fluorine unit to a fluorine unit carrying two bulky short side chains in a copolymer structure (P7, Figure 3a).[91] Copolymers with an increased content of bulky short side-chain fluorine units tended to disperse SWNTs with smaller chiral angles (such as $(10,3)$ with $\theta=12.7^{\circ}$ ) in comparison with those dispersed using PFO polymers (Table 2). [91]

Our group demonstrated the application of polythiophene (rr-P3ATs) for sorting semiconducting HiPco SWNTs with both high purity and a high yield (Figure 4d). [49] Specifically, we electrically measured 140 individual rr-P3ATs-sorted SWNTs and found them all to be semiconducting (purity >99\%).[63] The selectivity was explained by deriving a geometrical model representing a supramolecular structure with two strands of polymers wrapping around the SWNTs with interdigitated side chains. All of the experimentally observed sorted SWNTs were consistent with this model. [49]Several structurally similar polymers, such as PQT, rr-P3MDT and regiorandomP3DDT (Figure 4a), are not capable of dispersing SWNTs because the geometrical model cannot generate the necessary ordered conformation between the SWNTs and these polymers (Figure 4e). Increasing the side-chain length of our polythiophene could also increase the sorting yield to 20\% (Figure 4e). By introducing fused rings into the polymer backbone, the sorting yield of HiPco SWNTs could be further enhanced through better pi-pi stacking.[94] In addition, we found that the n-type polymer P(NDI2OD-T2) (Figure 4a) could also enable the selective dispersion of semiconducting HiPco SWNTs. [95] SWNTs sorted using P(NDI2OD-T2) have larger diameters than P3DDT-sorted SWNTs (Figure 4f), likely as a result of the stronger interaction between the large aromatic core of the P(NDI20D-T2) backbone and larger-diameter SWNTs. According to MD simulations in explicit toluene, the P(NDI20D-T2) backbone tends to follow the hexagonal path of the SWNT for various types of SWNTs. [95] 
(a)

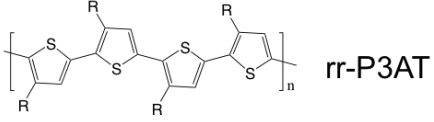

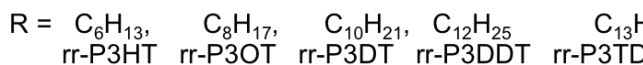

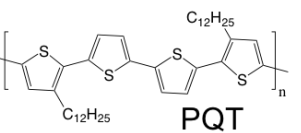

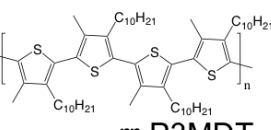
$\mathrm{C}_{8} \mathrm{H}_{17}$

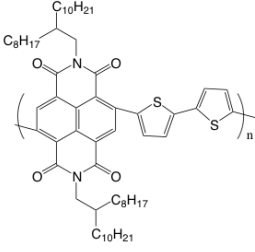

$\mathrm{P}(\mathrm{NDI}$ 2OD-T2)

(c)

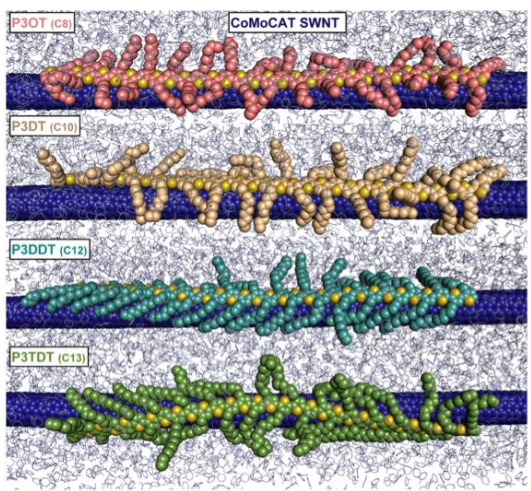

(e)

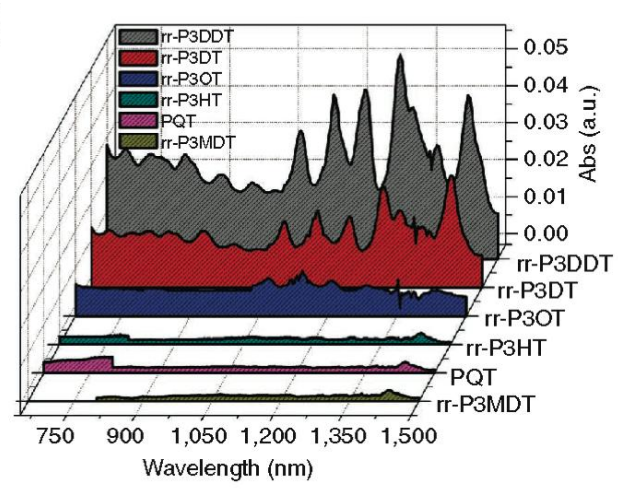

(b)

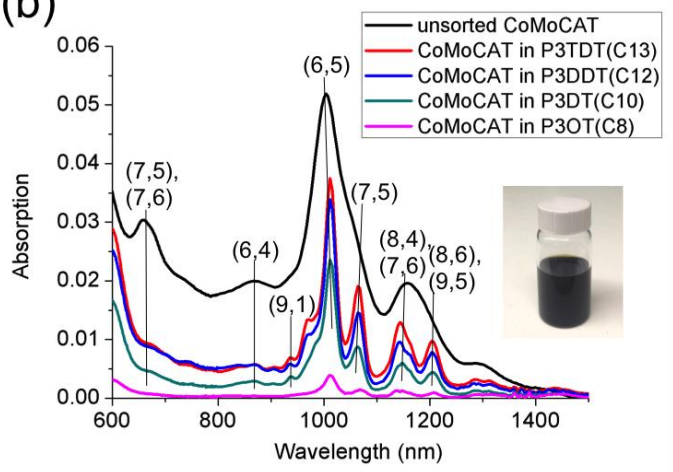

(d)

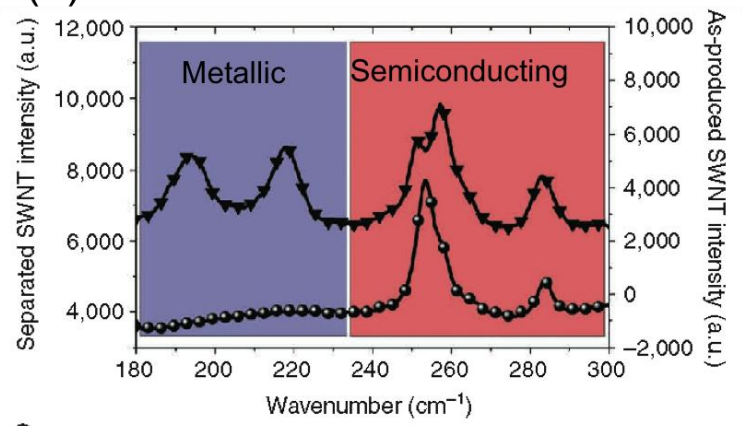

(f)

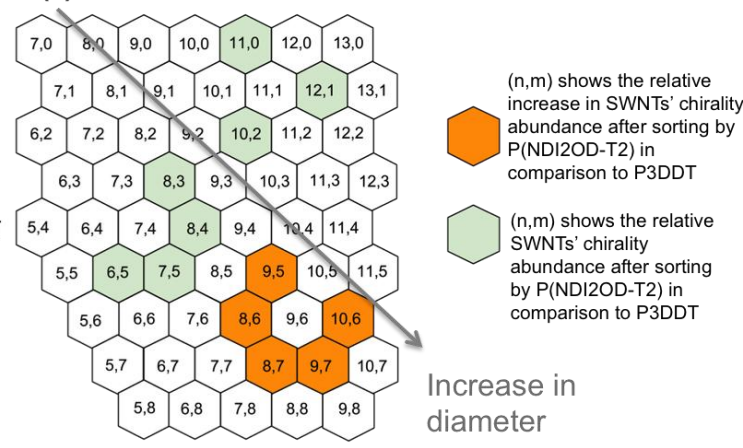

Figure 4. The sorting of CoMoCAT and HiPco SWNTs using polythiophene derivatives and the n-type P(NDI2OD-T2) polymer. (a) Chemical structures of the various polythiophene derivatives and the P(NDI20D-T2) polymer. (b) Comparison of the optical absorbance spectra for unsorted CoMoCAT SWNTs dispersed in N-methyl-2-pyrrolidone (NMP) and polythiophene-sorted SWNTs in toluene. The inset shows a solution of P3DDT-sorted SWNTs at a high concentration. [64] (c) Representative snapshots of the molecular dynamics (MD) simulations for $(6,5)$ SWNT with P3OT, P3DT, P3DDT and P3TDT in explicit toluene. [64] (d) Radial breathing mode (RBM) regions of resonant Raman scattering spectra at excitation energy of $1.96 \mathrm{eV}(633 \mathrm{~nm})$ : the upper profile (black triangle) and the lower profile (black sphere) represent the HiPco SWNTs before and after P3DDT sorting, respectively.[49] (e) Optical absorbance spectra of HiPco SWNTs sorted using various polythiophene derivatives in toluene. [49] (f) Chirality map showing the enrichment of HiPco SWNTs using P(NDI20D-T2) in comparison with HiPco SWNTs sorted using P3DDT. [95] Reprinted with permission from ref. 64, 49, 95. Copyright 2014 American Chemical Society, Copyright 2011 American Chemical Society, Copyright 2015 Wiley Online Library. 


\subsubsection{Laser ablation SWNTs}

For laser ablation SWNTs, Hennrich et al. reported that PFO (P1) enabled the high-purity sorting of $(9,7)$ SWNTs (Table 2).[86] With PFOPy (P8, Figure 3a), Tange et al. were able to sort primarily $(13,5)$ SWNTs, which have a diameter of $1.26 \mathrm{~nm}$ and an emission wavelength of $1500 \mathrm{~nm}$, which is ideal for telecommunication applications (Figure 3e, Table 2).[83] The author attributed the selectivity of this method to the wave-like chains of the polymer conformation around $(13,5)$ SWNTs based on MD simulations. [83] Berton et al. and Mistry et al. enhanced the sorting yield of semiconducting SWNTs by using several other types of polyfluorene-related copolymers, but they observed a reduced selectivity. [110-112] In particular, by using PFO-BPy (P2) as the sorting polymer, Mistry et al. achieved a sorting yield of up to 33\% while maintaining an excellent selectivity toward semiconducting SWNTs.[111]

\subsubsection{Arc-discharge SWNTs}

Arc-discharge SWNTs are the largest diameter tubes among the mass-produced SWNTs. These SWNTs are desirable for transistors because of their high intrinsic mobility and low Schottky barrier with metal contacts. $[113,114]$ Tange et al. found that P8BT (P7) can selectively enrich largediameter (15,4) SWNTs with a diameter of $1.38 \mathrm{~nm}$ (Figure 3f, Table 2).[84] They attributed this selectivity to the matching of the energy levels between the polymer and the selected SWNTs. We reported the use of dithiafulvalene/thiophene copolymers with a large-plane dithiafulvalene planar surface to form a stronger interaction with arc discharge SWNTs (Figure 5a).[115] To systematically investigate the effect of the dithiafulvalene unit, we varied the thiophene-to-dithiafulvalene ratios in the polymer (Figure 5b) of 3:1 (pDTFF-3T), 2:1 (pDTFF-2T) and 1:1 (pDTFF-1T), and found that the corresponding dispersion yields were $28 \%, 32 \%$ and $44 \%$, respectively. The increase in the sorting yield from pDTFF-3T to pDTFF-1T is attributed to the increase in the surface contact area between the polymer and the SWNTs, as indicated by MD simulations. [115] In addition, we also found that the sorted SWNT solutions remained stable, with no precipitation for at least 6 months. [115] 


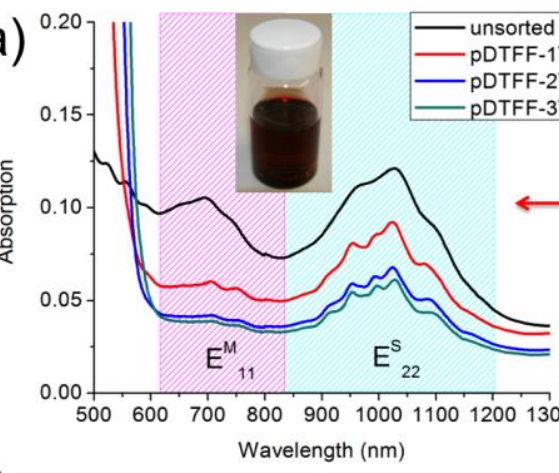

(c)

(d)

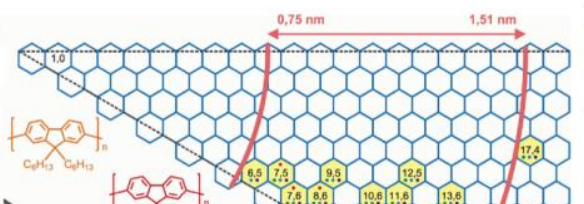

\section{(e)}

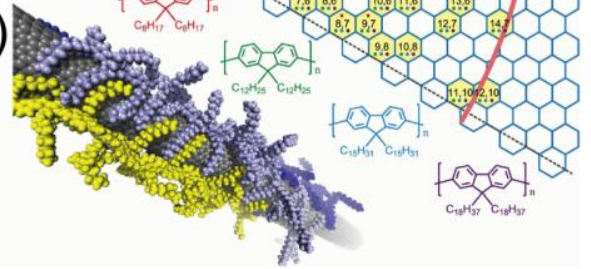

(b)

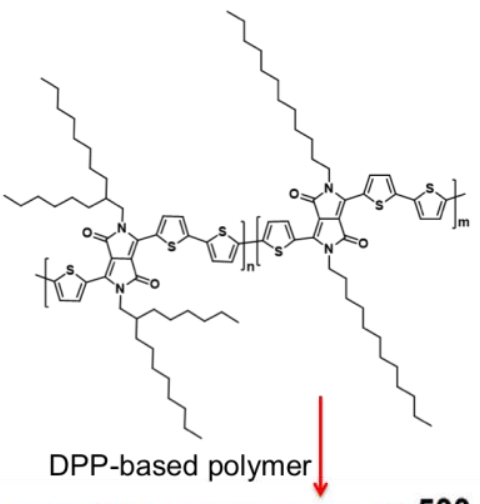

(f)

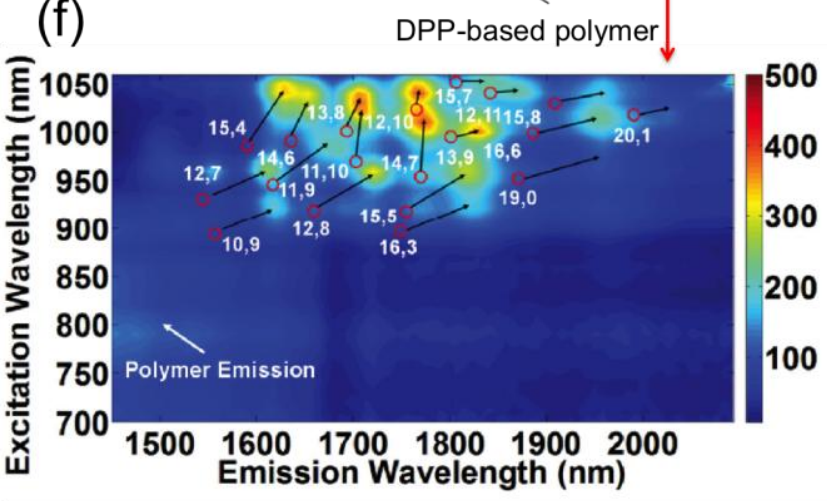

Figure 5 The sorting of large-diameter arc discharge SWNTs using various conjugated polymer structures. (a) Optical absorption spectra of unsorted SWNTs dispersed in N-methyl-2-pyrrolidone (NMP) and SWNTs sorted using pDTFF-mT. The inset shows a solution of pDTFF-3T-sorted SWNTs at a high concentration. [115] (b) Chemical structures of pDTFF-mT- and diketopyrrolopyrrole (DDP)based polymers. (c) Chirality map of SWNTs selected via wrapping with polyfluorene derivatives. The colors of the dots inside the hexagons indicate which of the polyfluorene derivatives are able to select SWNTs with that specific chirality (the color code corresponds to the chemical structures shown in Figure 5d). [116] (d) Chemical structures of polyfluorene derivatives with various sidechain lengths: PF6, PF8 (PFO), PF12(PFDD), PF15, and PF18. [116] (e) Molecular dynamics (MD) simulations of three PF12 chains wrapped around an SWNT. [116] (f) Photoluminescence excitation (PLE) maps showing the chirality of DPP polymer sorted SWNTs with diameter ranging from $1.3 \mathrm{~nm}$ to $1.6 \mathrm{~nm}$. [117] Reprinted with permission from ref. 115, 116, 117. Copyright 2013 American Chemical Society, Copyright 2013 Wiley Online Library, Copyright 2015 Wiley Online Library.

Gomulya et al. observed that similar to polythiophene, polyfluorenes with longer alkyl side chains produce better sorting yields. In addition, polyfluorenes with longer side chains enable better sorting of larger-diameter SWNTs (Figure 5c-e). [116] These authors found PF12 (PFDD) (Figure 5d) to be the most effective polymer for isolating individual SWNTs because it offered the highest photoluminescence yield compared with polyfluorenes of other side-chain lengths. [116] Notably, Brady et al. applied PFO-BPy (P2) as a sorting polymer for arc discharge semiconducting SWNTs and found the impurity of metallic SWNTs to be less than one part per 5519 (purity > 99.98\%). [118] More recently, we reported the selective dispersion of SWNTs with diameters of approximately 1.5 
nm using a high-mobility diketopyrrolopyrrole (DDP)-based donor-acceptor polymer (Figure 5b,f). [117] The effects of the linear vs. branched side chain on the dispersion yield and selectivity were investigated in detail in this study. [117]

\subsection{Effects of the solvent}

The selection of the solvent is an important factor determining both the purity and yield of sorted semiconducting SWNTs. A few criteria should be considered when selecting a solvent for the selective dispersion of SWNTs: (1) the solvent should have a good solubility for the conjugated polymer used for sorting; (2) SWNTs should have low intrinsic solubility in the solvent, such that only polymer-wrapped SWNTs can be dispersed in solution; and (3) the solvent should have a lower density than SWNTs $\left(1.33 \mathrm{~g} \mathrm{~cm}^{-2}\right)$ to allow the SWNT bundles to sediment after centrifugation. For example, Hwang et al. studied several solvents for sorting SWNTs with PFO and observed that highdensity solvents, such as chloroform (density of $1.5 \mathrm{~g} \mathrm{~cm}^{-3}$ ), do not achieve the selective dispersion of semiconducting SWNTs. They attributed this behavior to the bundled SWNTs remaining in the solution after centrifugation because of buoyant forces.[119] For the sorting of SWNTs with P3DDT, we compared six solvents (Table 3 ) that satisfied the 3 criteria listed above and found that the more polar THF is the only solvent that does not selectively disperse semiconducting SWNTs (more discussion in section 1.6).[120] The other 5 solvents can all be used for the selective dispersion of semiconducting SWNTs, and the sorting yield of semiconducting SWNTs can be improved to over $40 \%$ by utilizing $o$-xylene or decalin as the sorting solvents. Using these alternative solvents, we can also produce semiconducting SWNT inks with a range of boiling points (from $111^{\circ} \mathrm{C}$ to $207^{\circ} \mathrm{C}$ ), viscosities (from $0.59 \mathrm{cP}$ to $2.09 \mathrm{cP}$ ), and surface tensions (from $28.4 \mathrm{mN} \mathrm{m}^{-1}$ to $34.3 \mathrm{mN} \mathrm{m}^{-1}$ ) and low toxicities (rat LD $\mathrm{L}_{50}$ (oral) up to $4988 \mathrm{mg} \mathrm{kg}^{-1}$ ) (Table 3), which are important parameters for their use in printed electronics. [120] 


\begin{tabular}{|c|c|c|c|c|}
\hline Solvent & $\begin{array}{l}\text { Viscosity } \\
\text { (cP) }\end{array}$ & $\begin{array}{l}\text { Boiling } \\
\text { point }\left({ }^{\circ} \mathrm{C}\right)\end{array}$ & $\begin{array}{l}\text { Surface } \\
\text { tension } \\
\left(\mathrm{mN} \mathrm{m}^{-1}\right)\end{array}$ & $\begin{array}{l}\text { Toxicity, } \\
\text { rat LD } \\
\mathrm{kg}^{-1} \text { ) }\end{array}$ \\
\hline Toluene & 0.59 & 111 & 28.4 & 636 \\
\hline$m$-Xylene & 0.62 & 139 & 28.9 & 4988 \\
\hline$o$-Xylene & 0.81 & 144 & 30.1 & 3567 \\
\hline Tetralin & 2.02 & 207 & 34.3 & 2860 \\
\hline Decalin & 2.09 & 190 & 31.5 & 4170 \\
\hline THF & 0.48 & 66 & 26.4 & 1650 \\
\hline
\end{tabular}

Table 3. Properties of the solvents used to sort SWNTs with P3DDT. Data quoted from Wikipedia or the relevant Materials Safety Data Sheet (MSDS). [120] Reprinted with permission from ref. 120. Copyright 2015 Wiley Online Library.

\subsection{Effects of the polymer-to-SWNTs ratio}

The polymer-to-SWNTs ratio is used for sorting is another factor that influences both the purity and sorting yield of the semiconducting SWNTs in the final solution.[111, 121] In particular, Ding et al. systematically increased the mass ratio of PFDD to laser ablation SWNTs from 0.25 to 8 in toluene and observed that the sorting yield also increased from $0.7 \%$ to $20.4 \%$ (Figure 6a), likely as a result of the increased number of individual SWNTs with more polymer screening. However, this increased yield resulted in a decreased purity of semiconducting SWNTs, as indicated by both UV-Vis-NIR spectroscopy and Raman spectroscopy (Figure 6a,b). [121] A similar trend has also been observed for the DPP-enabled sorting of arc discharge SWNTs (more discussion in section 1.6). [117]

\subsection{Effects of the sonication temperature}

The temperature during the sonication process also influences the sorting yield of semiconducting SWNTs. $[49,122,123]$ We varied the temperature during the ultrasonication process from $-40^{\circ} \mathrm{C}$ to $90^{\circ} \mathrm{C}$ and discovered that the sorting yield of P3DDT sorted SWNTs increased from its initial value at $-40^{\circ} \mathrm{C}$ to a maximum at $50^{\circ} \mathrm{C}$ and then continuously decreased as the temperature was increased further. [49] The occurrence of a maximum yield at $50^{\circ} \mathrm{C}$ can likely be attributed to the competition 
between the thermodynamic and kinetic effects illustrated below (Figure 6c).[49] At high temperatures, the polymer side-chain fluctuations might prevent the polymer from forming a wrapped supramolecular structure with the SWNTs because it is entropically more favorable for the polymers to explore a multitude of conformations. By contrast, at low temperatures, the polymer wrapping is kinetically limited because of the lack of conformational freedom of the polymer backbones; therefore, the wrapping process cannot occur because of the energy barrier for the dissolution of the polymer. The polymer wrapping of SWNTs can occur only when the polymers have sufficient freedom to dissolve in the solution and sufficient thermodynamic stability to wrap around the SWNTs. [49] The results of a recent study on the PFO sorting of HiPco SWNTs at various temperatures suggest that increased temperatures might promote the sorting of large-diameter SWNTs. [122] 

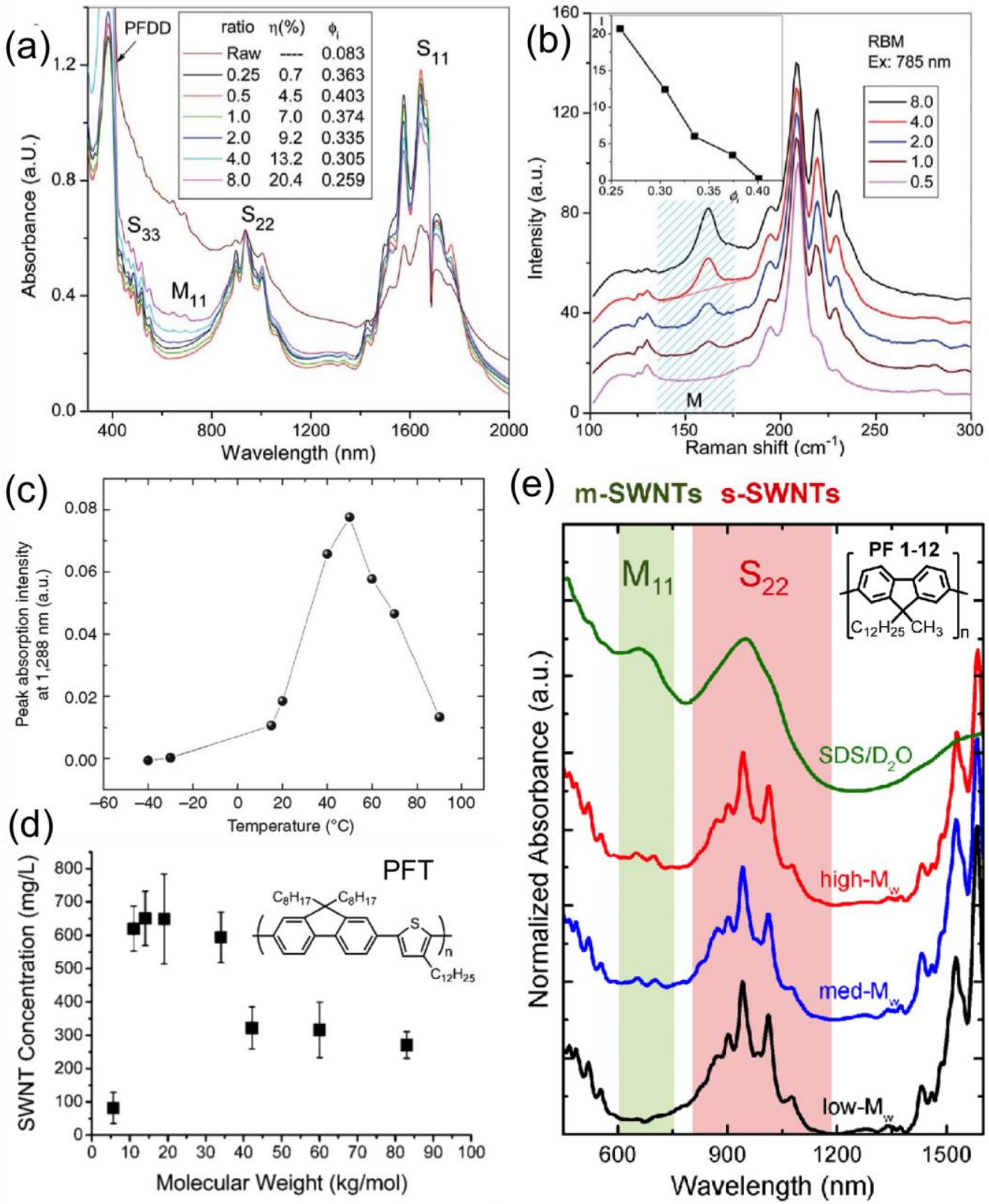

(e)

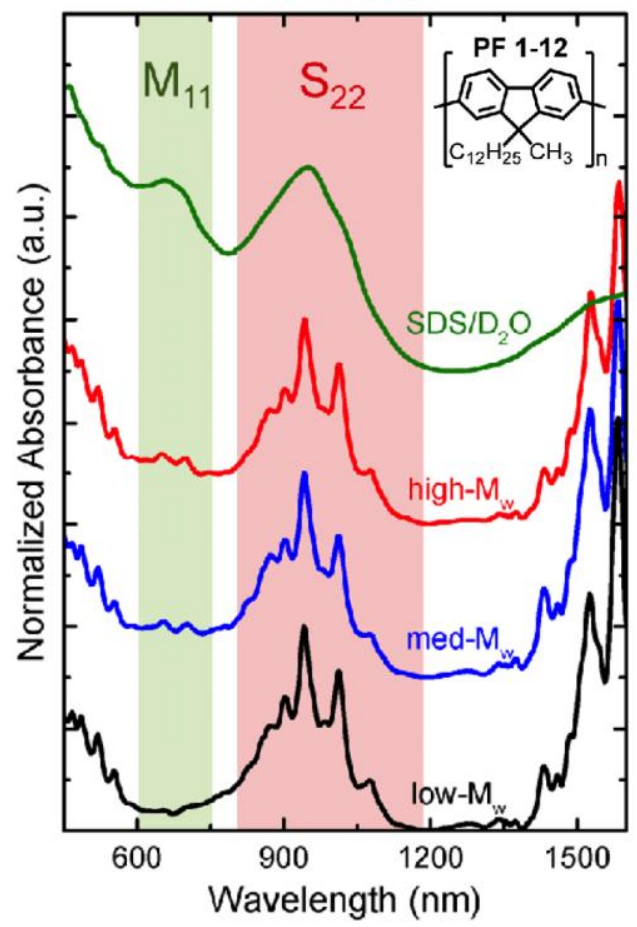

Figure 6 Effects of the polymer-to-SWNT ratio, temperature and polymer molecular weight on the sorting of SWNTs. (a) Absorption spectra and (b) Raman spectra of the Radial breathing mode (RBM) region excited at $785 \mathrm{~nm}$ for SWNTs sorted using PFDD at polymer-to-SWNTs ratios of 0.25, 0.5, 1.0, 2.0, 4.0, and 8.0 in toluene. [121] (c) Absorption intensities at $1288 \mathrm{~nm}$ for SWNTs sorted with P3DDT in toluene, with sonication temperatures ranging from $40^{\circ} \mathrm{C}$ to $90^{\circ} \mathrm{C}$. [49] (d) SWNT concentration as a function of PFT polymer molecular weight in THF. The error bars represent the standard deviations determined from 3 separately prepared samples. [124] (e) Normalized absorbance spectra of unsorted SWNTs and SWNTs sorted using PF-1-12 polymers with different molecular weights.[125] Reprinted with permission from ref. 121, 49, 124, 125. Copyright 2014 Royal Society of Chemistry, Copyright 2011 Nature Publishing Group, Copyright 2011 Royal Society of Chemistry, Copyright 2015 American Chemical Society. 


\subsection{Effects of the polymer molecular weight}

The polymer molecular weight also affects both the dispersion yield and the purity in the sorting of semiconducting SWNTs.[126] [124] In the case of oligomers of PFO, at least 6 fluorene units are required to achieve any dispersion, and the dispersion increases with increasing molecular weight. [126] However, the range of polymer molecular weights $\left(M_{n}\right)$ investigated in the cited study was relatively small $\left(\mathrm{M}_{\mathrm{n}}<13 \mathrm{~kg} \mathrm{~mol}^{-1}\right)$. [126] Imin et al. synthesized poly[2,7-(9,9-dioctylfluorene)-alt-2,5(3-dodecylthiophene)] (PFTs) with molecular weights varying from $5.7 \mathrm{~kg} \mathrm{~mol}^{-1}$ to $83 \mathrm{~kg} \mathrm{~mol}^{-1}$ and observed high sorting yields for $\mathrm{M}_{\mathrm{n}}$ values ranging from $10 \mathrm{~kg} \mathrm{~mol}^{-1}$ to $35 \mathrm{~kg} \mathrm{~mol}^{-1}$ (Figure 6d). [124] Much lower yields were observed for $\mathrm{M}_{\mathrm{n}}$ values below $10 \mathrm{~kg} \mathrm{~mol}^{-1}$ or above $35 \mathrm{~kg} \mathrm{~mol}^{-1}$. The low sorting yield at low $\mathrm{M}_{\mathrm{n}}$ is attributed to a weaker pi-pi interaction between the oligomers and the SWNT surfaces; therefore, the majority of SWNTs cannot be dispersed. At high $M_{n}$, the polymers are expected to demonstrate lower solubility and hence to aggregate rather than interact with the SWNTs, also resulting in a lower dispersion yield. The SWNT sorting yields achieved using PFDD also exhibit a similar dependence on molecular weight.[121] The selectivity for semiconducting SWNTs is also affected by the polymer molecular weight, as observed by Schießl et al.: increasing the molecular weight of the atactic poly(9-dodecyl-9-methyl-fluorene) (PF-1-12) polymer resulted in a reduction in the purity of the sorted semiconducting SWNTs (Figure 6e). [125] The authors attributed this reduction to the increased viscosity of the high-molecular-weight polymer solution (more discussion in section 1.6). [87, 125]

\subsection{Proposed mechanism for the polymer sorting of semiconducting SWNTs}

Based on the current studies, all of the investigated conjugated polymers (both p-type and n-type) appear to result in the enrichment of semiconducting SWNTs. The major factors that influence the purity of the semiconducting SWNTs include the polarity of the solvent, the polymer-to-SWNT ratio and the molecular weight of the polymer. We propose that the selective dispersion of semiconducting SWNTs occurs as result of the difference in polarity between semiconducting and metallic SWNTs. Because metallic SWNTs are several orders of magnitude more polarizable than semiconducting 
SWNTs, stronger temporary dipoles are likely to form between the polymers and these SWNTs. [120] In a modeling study, Kanai et al. demonstrated stronger charge transfer between P3HT and metallic SWNTs in comparison with that between P3HT and semiconducting SWNTs,[127] consistent with our hypothesis that stronger dipoles form in polymer-wrapped metallic SWNTs. Therefore, after the sonication process, polymer-wrapped metallic SWNTs display a higher likelihood to bundle and sediment after centrifugation, whereas individual polymer-wrapped semiconducting SWNTs remain in suspension.

When a polar solvent such as THF is used, both metallic and semiconducting SWNTs are dispersed (as shown in section 1.2). This difference is not caused by a higher intrinsic solubility of SWNTs in THF because SWNTs have a similar solubility in both THF (4.9 $\left.\mathrm{mg} \mathrm{L}^{-1}\right)$ and $o$-xylene $\left(4.7 \mathrm{mg} \mathrm{L}^{-1}\right)$, [128] the latter is an excellent solvent for selective dispersion of semiconducting SWNTs. We believe that the reason for this difference is that the more polar nature of THF results in stronger interactions between the THF and the more polarizable polymer-wrapped metallic SWNTs. This process screens the dipole interaction between the polymer-wrapped metallic SWNTs and prevents them from aggregating. As a result, the polymer-wrapped metallic SWNTs also remain in the supernatant. The selectivity toward semiconducting SWNTs also reduces with an increase in the polymer-to-SWNT ratio (as shown in section 1.3), accompanied by an increase in the sorting yield. This observation is likely because of the additional polymers wrapped around the metallic SWNTs, which screen their interactions and hence prevent their aggregation. As a result, more individual polymer-wrapped metallic SWNTs also remain in the supernatant. This proposed mechanism is also consistent with the molecular-weight-driven trend observed by Schießl et al. [125] (section 1.5): the higher viscosity of a higher-molecular-weight polymer solution slows the aggregation of the metallic SWNT-polymer hybrids, resulting in less selective dispersion of semiconducting SWNTs.[125] 


\section{Applications of polymer-sorted semiconducting SWNTs}

\subsection{Thin film transistors}

\subsubsection{Transistors with Random network}

SWNTs are desirable for thin film transistors due to their excellent charge transport mobility and low-cost solution processiblity. For SWNT random network transistors, it is important to report the mobility and on/off ratio of the transistor at the same time since they are both affected by the density of SWNT network and channel length. [129-131] Higher density or smaller channel length of SWNT networks tend to have a higher mobility but lower on/off ratio, in particular for low purity SWNT transistors. [129-131] A number of research groups have utilized polymer-sorted semiconducting SWNTs for fabrication of random network transistors. [49, 121, 132-134] We reported the fabrication of P3DDT-sorted HiPco SWNT transistors with a mobility of up to $12 \mathrm{~cm}^{2} \mathrm{~V}^{-1} \mathrm{~s}^{-1}$ and an on/off ratio of $10^{6}$ without any post-treatment. [49] The soaking process developed by our group is compatible with the wafer-scale manufacture of devices. [135]By unitizing P3DDT-sorted large-diameter arc discharge SWNTs, the device mobility can be enhanced to $\sim 34 \mathrm{~cm}^{2} \mathrm{~V}^{-1} \mathrm{~s}^{-1}$ while maintaining an on/off ratio of $10^{7}$. [134] Rinsing several times with toluene followed by annealing at $150^{\circ} \mathrm{C}$ for $30 \mathrm{~min}$ improved the device performance. Last year, Ding et al. reported a mobility of up to $58 \mathrm{~cm}^{2} \mathrm{~V}^{-1} \mathrm{~s}^{-1}$ with an on/off ratio of $10^{4}$ in a dense PFDD-sorted SWNT network using the drop casting method followed by rinsing with toluene. [121] Among the 25 devices measured, the average mobility was 26 $\pm 14 \mathrm{~cm}^{2} \mathrm{~V}^{-1} \mathrm{~s}^{-1}$ with an average on/off ratio of $\sim 10^{6} .[121]$

\subsubsection{Transistors with Aligned SWNTs}

In order to enhance charge transport further, two techniques have been developed for the assembly of polymer-sorted SWNTs.[136] To align PFO-BPy-sorted arc discharge SWNTs, Joo et al. developed a technique called "dose-controlled, floating evaporative self-assembly" (FESA),[137] in which doses of sorted SWNTs in organic solvents were dropped into the vicinity of a receiving substrate being withdrawn from a water bath at a certain velocity (Figure 7a). Stripes of aligned SWNTs instantaneously formed across the entire width of the substrate after each dose (Figure 7b). Using

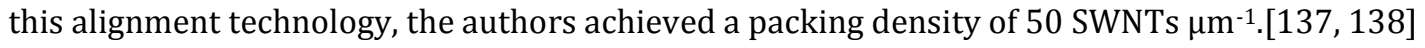



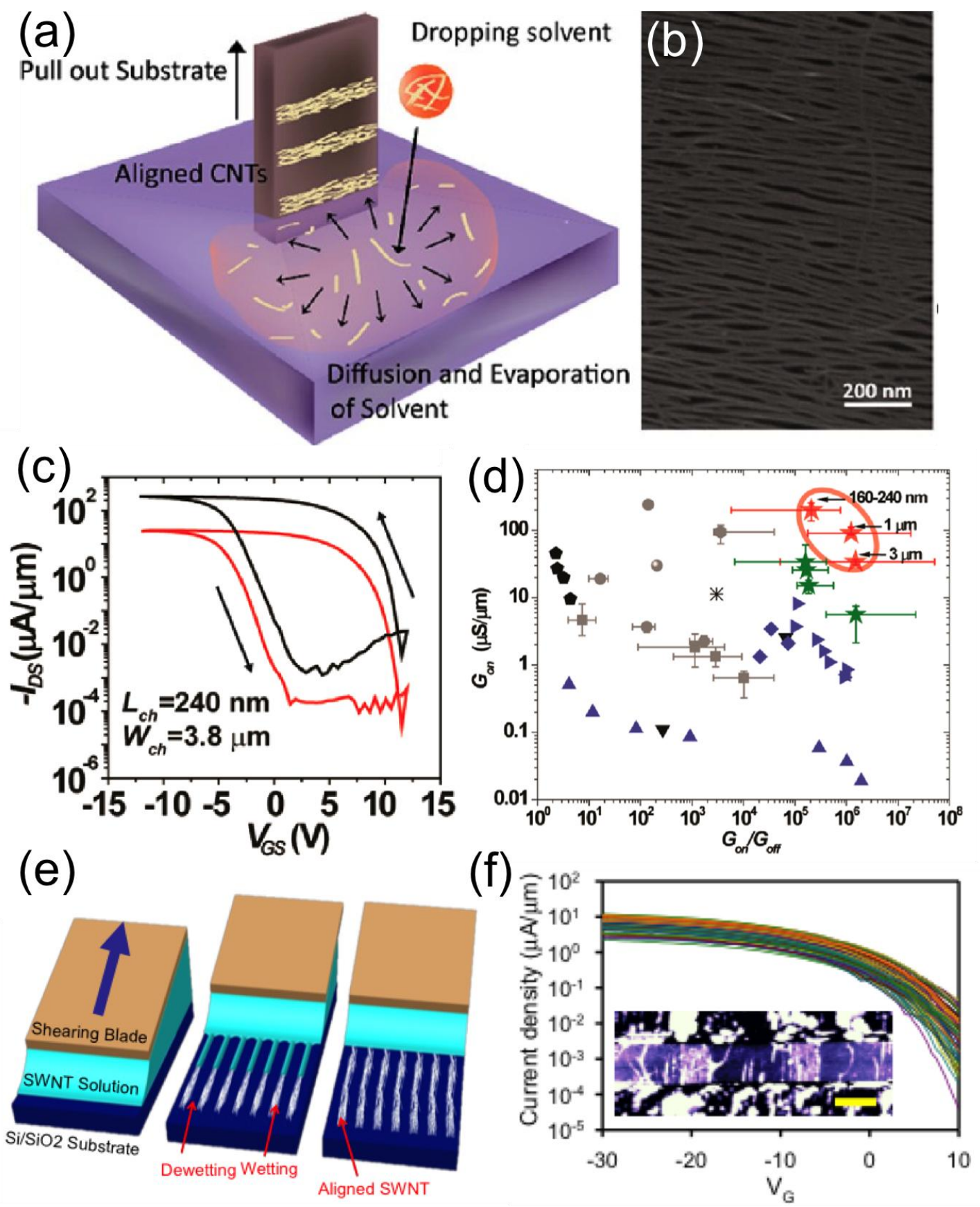

Figure 7 Assembly of polymer-sorted SWNTs for high-performance transistor applications. (a) Schematic illustration of the process used to fabricate aligned SWNTs via a dose-controlled, floating evaporative self-assembly (FESA) process. [137] (b) A high-resolution SEM image of the aligned SWNTs. [137] (c) Transfer characteristics at $\mathrm{V}_{\mathrm{SD}}=-1 \mathrm{~V}$ (black) and $-0.1 \mathrm{~V}$ (red) for a highperformance SWNT transistor with $\mathrm{L}=240 \mathrm{~nm}$ and $\mathrm{W}=3.8 \mu \mathrm{m}$. [118] (d) $\mathrm{G}_{\text {on }}$ per width vs. the on/off ratio of the device using FESA process (red stars) other results cited in ref 101. [118] (e) Schematic diagram of SWNT alignment using a solution-based shearing method. [136] (f) Transfer characteristics of 75 shear-aligned SWNT transistors. The inset is an AFM image of one of the transistors in the channel region. The scale bar represents $600 \mathrm{~nm}$. [136] Reprinted with permission from ref. 137, 118, 136. Copyright 2014 American Chemical Society, Copyright 2014 American Chemical Society, Copyright 2015 Wiley Online Library. 
With further optimization of the SWNT processing and device fabrication processes, Brady et al. reported a record conductance of $261 \mu \mathrm{S} \mu \mathrm{m}^{-1}$ at an on/off ratio of $2 \times 10^{5}$ and a channel length of $240 \mathrm{~nm}$ (Figure 7c).[118] This performance surpassed that of any other state-of-the-art SWNT transistor,[139-141] demonstrating both the excellent selectivity of the polymer-sorting method and the effectiveness of the alignment method (Figure 7d). [118] The mobility of the aligned SWNT transistors was calculated to be $179 \pm 10 \mathrm{~cm}^{2} \mathrm{~V}^{-1} \mathrm{~s}^{-1}$ at a channel length of $3 \mu \mathrm{m}$. [118] Our group developed a large-scale solution shearing method for aligning P3DDT-sorted HiPco SWNTs. In this method, a sorted SWNT solution is sandwiched between a shearing blade and a wafer with alternating patterns of solvent wetting and dewetting regions (Figure 7e). As the shearing blade moves, the solution meniscus separates and dries, depositing densely aligned SWNTs on the solvent wetting regions. We achieved a packing density of 150 200 SWNTs $\mu \mathrm{m}^{-1}$ over a $100 \mu \mathrm{m}$ x $100 \mu \mathrm{m}$ area and observed a high uniformity of device performance using these shear-aligned SWNTs

(Figure 7f). The average on conductance and on/off ratios were $10.08 \mu \mathrm{S} \mu \mathrm{m}^{-1}$ and $1.53 \times 10^{3}$, respectively. [136]

\subsubsection{Stability of transistors}

One of the major challenges to be overcome for the practical use of SWNT transistors in circuit applications is the reduction of the large operational hysteresis $[142,143]$ that is caused primarily by charge traps on the surface and in the gate dielectrics. $[142,144]$ One demonstrated method is to increase the polymer-to-SWNT ratio for sorting to ensure that sufficient polymers can wrap around the dispersed SWNTs. Liu et al. used F8BT at a ratio of 5:1 with respect to the amount of HiPco SWNTs and achieved low-hysteresis devices via a dip-coating method. [143] Of the 40 devices they measured at a gate-induced field of $1.33 \mathrm{MV} \mathrm{cm}^{-1}$, all displayed a hysteresis gap $\left(\Delta \mathrm{V}_{\mathrm{H}}\right)$ of less than 2.5 $\mathrm{V}$ under a gate sweep from $20 \mathrm{~V}$ to $-20 \mathrm{~V}$. The second method is to use the top-gate device geometry, in which a layer of polymer is coated on top of the SWNT film. We utilized fluorinated polymers as our top-gate dielectrics because they are known to be resistant to moisture, which is one of the 
primary causes of hysteresis (Figure 8a).[145] Poly(trifluoroethylene) (PTrFE) was used because it is a non-ferroelectric material and therefore does not induce intrinsic hysteresis and because it possesses a high dielectric constant of 10. By utilizing PTrFE as the top-gate dielectric, we succeeded in fabricating hysteresis-free TFTs with a threshold voltage of approximately $0 \mathrm{~V}$ in ambient conditions. These devices can demonstrate hysteresis-free operation at various sweep rates at a gate field of $0.5 \mathrm{MV} / \mathrm{cm}$ under ambient atmosphere (Figure $\mathbf{8 b}$ ). The 24 devices all displayed hysteresis gap $\left(\Delta \mathrm{V}_{\mathrm{H}}\right)$ of less than $0.7 \mathrm{~V}$ under a gate sweep from $10 \mathrm{~V}$ to $-10 \mathrm{~V}$ (Figure 8c). [145] Additionally, we tested the electrical bias in rigorous stress tests (Figure 8d) lasting $10000 \mathrm{~s}$; the threshold voltage shifts of our SWNT transistors were comparable to those of recently reported highly stable organic/metal oxide transistors. [145]

\subsubsection{Ambipolar transistors}

SWNT transistors generally exhibit p-type behavior in air as a result of Oxygen doping. However, SWNT transistors are intrinsically ambipolar and their ambipolar characteristics can be observed in an inert environment. Ambipolar transistors fabricated from PFO-sorted CoMoCAT SWNTs and PFDD-sorted HiPco and arc discharge SWNTs were measured under a nitrogen atmosphere by the Loi group. $[116,133]$ They achieved a hole mobility of $14 \mathrm{~cm}^{2} \mathrm{~V}^{-1} \mathrm{~s}^{-1}$ and an electron mobility of 16 $\mathrm{cm}^{2} \mathrm{~V}^{-1} \mathrm{~s}^{-1}$ for arc discharge SWNTs when an ion gel was used as the dielectric for their devices. [116] Notably, the devices exhibited a steep sub-threshold swing (SS) of $70 \mathrm{mV} \mathrm{dec}^{-1}$ for hole accumulation and an SS of $110 \mathrm{mV} \mathrm{dec}^{-1}$ for electron accumulation, demonstrating the excellent coupling between the ion-gel gates and the SWNT films. Ambipolar devices are also obtained when the fluorinated high- $k$ polymer $\mathrm{P}(\mathrm{VDF}-\mathrm{TrFE}-\mathrm{CTFE}),[145] \mathrm{Al}_{2} \mathrm{O}_{3},[146]$ or $\mathrm{HfO}_{\mathrm{x}}[125,147]$ is used as the top-gate dielectric under ambient conditions. The ambipolar characteristics of SWNT transistors are generally not desirable for traditional CMOS technology since theses devices can not be switched off completely. However, the ambipolar characteristics can be utilized for the fabrication of SWNT CMOS-like logic circuits without the need for n-doping of the SWNTs, thereby simplifying the circuit fabrication process.[95, 147, 148] 

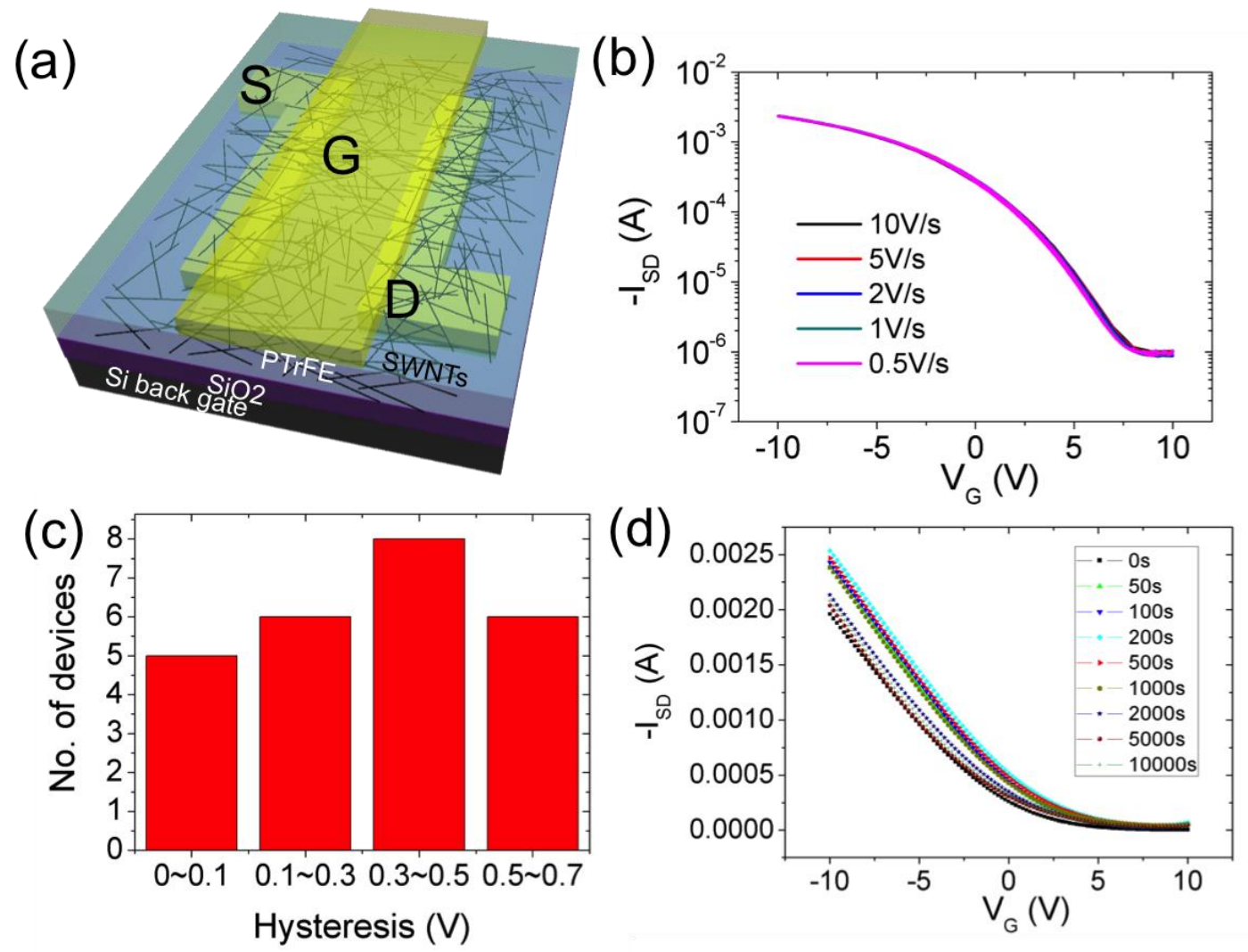

Figure 8 Stability and stretchablitiy performance of polymer-sorted SWNT random network transistors. (a) Schematic diagram of the device structure of an SWNT top-gate transistor with poly(trifluoroethylene) (PTrFE) as the top-gate dielectric. [145] (b) Sweep-rate-dependent top-gate transfer characteristics of an SWNT transistor at $V_{S D}=-5$ V. [145] (c) Histogram of the hysteresis of 24 devices with a PTrFE top-gate dielectric. [145] (d) Bias-stress testing of SWNT top-gate TFTs under a gate bias of $-10 \mathrm{~V}$ and $\mathrm{V}_{\mathrm{SD}}=-5 \mathrm{~V}$. [145] Reprinted with permission from ref. 145. Copyright 2014 Wiley Online Library.

\subsubsection{Printed transistors}

Printing is a patterning method for fabricating electronics that is lower in cost and enables the patterning of larger areas compared with traditional lithography-based methods. $[149,150]$ Printed polymer-sorted SWNTs transistor were demonstrated using both P3DDT-sorted SWNTs and PFO-BTsorted SWNTs.[120, 134, 151] A mobility of $34.8 \mathrm{~cm}^{2} \mathrm{~V}^{-1} \mathrm{~s}^{-1}$ and an on/off ratio of $10^{5}$ were achieved simultaneously using aerosol jet-printed arc discharge SWNTs. [151] Oxygen plasma treatment was reported to improve the wetting of the printed SWNTs and therefore to improve the device uniformity.[146] These transistors were also used to switch a single-pixel organic light-emitting 
diode (OLED), thereby demonstrating their potential for use in printed, flexible display applications. [152] In addition, with $\mathrm{HfO}_{\mathrm{x}}$ as the top-gate dielectric, an ambipolar device with a hole mobility of $46.2 \mathrm{~cm}^{2} \mathrm{~V}^{-1} \mathrm{~s}^{-1}$, an electron mobility of $33.2 \mathrm{~cm}^{2} \mathrm{~V}^{-1} \mathrm{~s}^{-1}$, an on/off ratio of $10^{5}$ and a threshold swing of $109 \mathrm{mV} \mathrm{dec}{ }^{-1}$ was demonstrated on a flexible substrate.[147]

\subsubsection{Stretchable transistors}

Stretchable transistors are desirable for applications such as health monitoring devices[153-155] and stretchable displays.[156] SWNTs networks are desirable for this application due to the excellent mechanical properties of nanotubes[157] and the possibility of sliding and buckling of the network. [12] Xu et al. utilized PFO-sorted CoMoCAT SWNTs for fabrication of stretchable transistors.[158] The process involved using a buckled SWNT film as the active channel, followed by coating with a flexible ion gel as a stretchable dielectric layer and a buckled metal layer to manufacture the electrodes (Figure 9a). Stretchable devices with mobilities of up to $10 \mathrm{~cm}^{2} \mathrm{~V}^{-1} \mathrm{~s}^{-1}$ and on/off ratios of greater than $10^{4}$ were demonstrated at operating voltages below $2 \mathrm{~V}$. The devices exhibited stable performance under strains of up to 50\% and repeated mechanical cycling (Figure 9b). [158] Our group has improved the robustness of SWNT stretchable transistor further by using thermoplastic polyurethane as dielectrics and substrates. P3DDT-sorted semiconducting SWNTs and unsorted SWNTs were used as both semiconductor and electrodes respectively (fabrication process shown in Figure 9c). [159] Devices were stretched to $100 \%$ strain and similar strain-dependent transport behavior was observed when the devices are stretched in parallel and perpendicular directions. Little change in device performance was observed after stretching the devices at $100 \%$ strain for 1000 cycles. (Figure 9d) Additionally, these devices can survive under pressure of at least $75 \mathrm{kPA}$, sudden impacts, puncture, tears and even stretching after cut (Figure 9e). [159] 
(a)

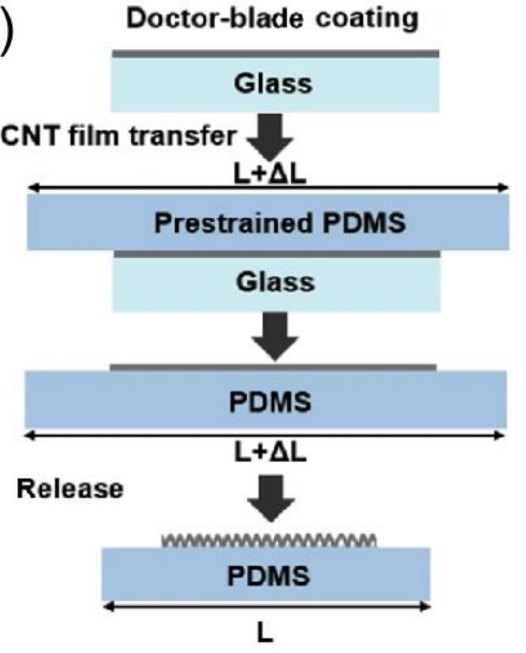

(c)

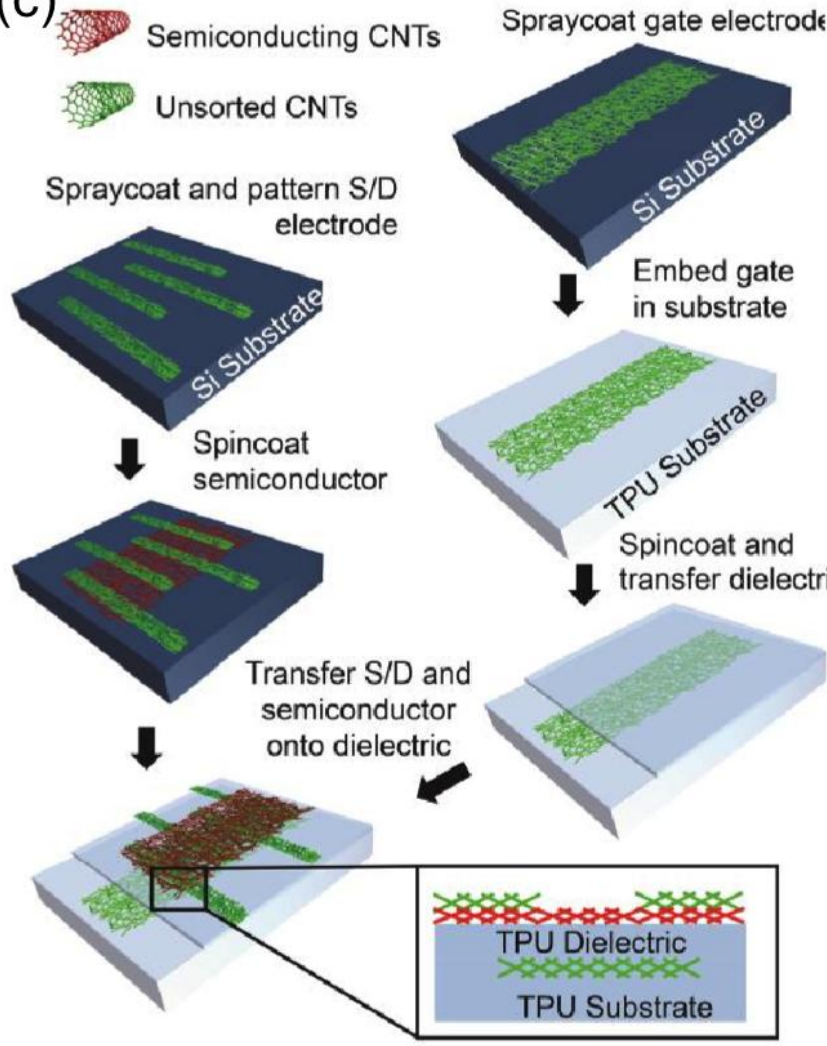

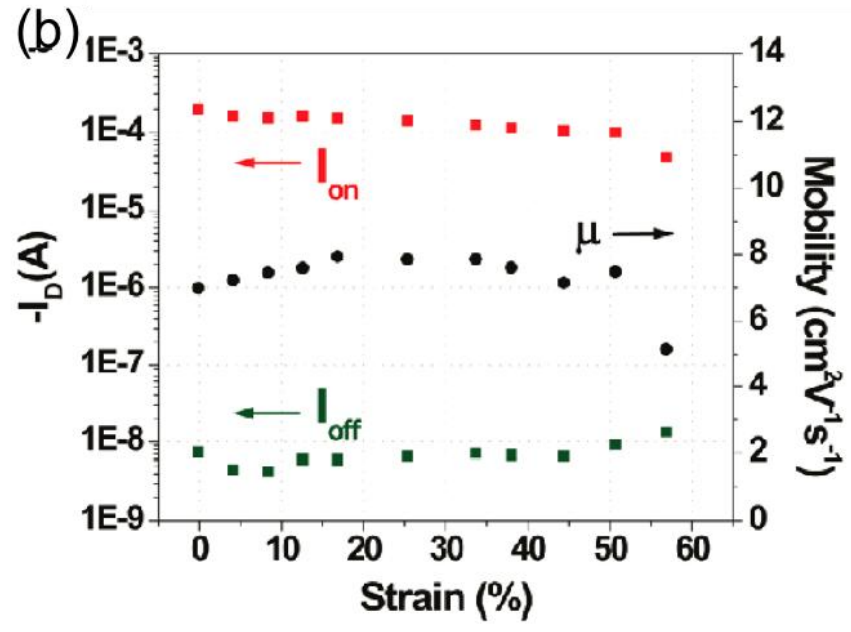

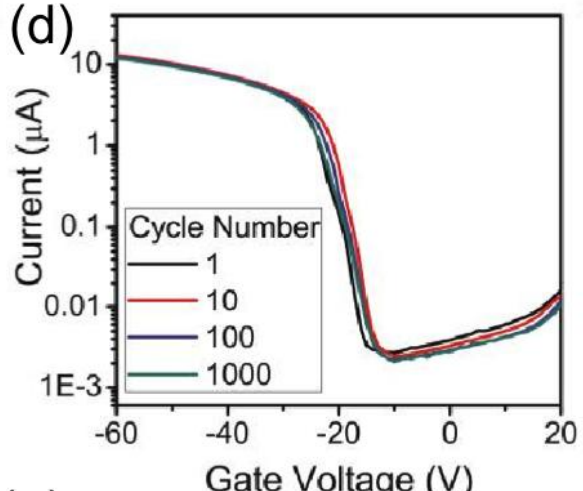

(e)

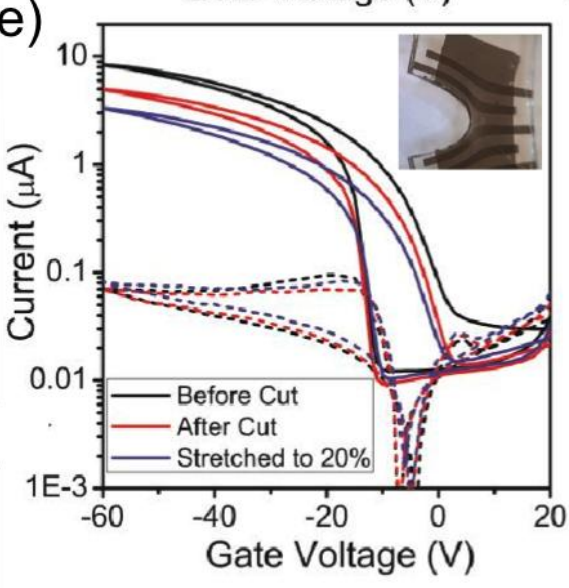

Figure 9 (a) Schematic illustration of the transfer and buckling of SWNT films. [158] (b) On currents, off currents and mobility as functions of the applied strain for a device stretched by more than $50 \%$. [158] (c) Fabrication process for SWNT durable and stretchable transistors. [159](d) Transfer characteristic of a SWNT device that was cycled to $100 \%$ strain. [159] (e) Transfer curves for a SWNT device that was cut and then stretched to $20 \%$ strain, Inset shows the image of the cut device. [159]Reprinted with permission from ref. 158, 159. Copyright 2014 American Chemical Society, Copyright 2015 Wiley Online Library. 


\subsection{Logic circuits}

With better control in devices characteristics, polymer-sorted SWNTs transistors have also been applied for constructing logic circuits. Several basic components of logic circuits (such as inverters, NAND gates, NOR gates and ring oscillators) have been demonstrated using polymer-sorted SWNTs on flexible substrates. A flexible inverter can be constructed using only p-type SWNT transistors, $[134,160]$ ambipolar SWNT transistors $[95,146,147]$ or a combination of p-type and ndoped SWNT transistors.[161] This last type of inverter, which is known as a CMOS inverter, is ideal for achieving a high noise margin (a measure of the immunity of a logic circuit against noise) because the threshold voltage of the n-type transistor can be controlled to achieve symmetric output from both types. We recently reported the continuous threshold voltage tuning of a transistor fabricated with P3DDT-sorted SWNTs by means of doping with $1 \mathrm{H}$-benzoimidazole derivatives, which allowed us to achieve symmetric threshold voltages and current outputs (Figure 10a,b). [161] As a result of this tunable doping, we fabricated flexible CMOS inverter with a noise margin of $72 \%$ of $1 / 2 V_{D D}$ (Figure 10c), which is among the highest reported noise margin for flexible CMOS inverters achieved with all materials. Additionally, we fabricated flexible CMOS NAND/NOR logic gates with a rail-to-rail output voltage swing and sub-nanowatt power consumption (Figure 10d), as a result of low offcurrent of polymer-sorted SWNT transistors.[161] Xu et al. also applied ambipolar PFO-BT-sorted semiconducting SWNT transistors for the fabrication of printed inverters, logic gates and ring oscillators (Figure 10e,f) with an oscillator frequency of $1.7 \mathrm{kHz}$ at $\mathrm{V}_{\mathrm{DD}}=2 \mathrm{~V}$ on a flexible substrate (Figure 10g).[147] 
(a)

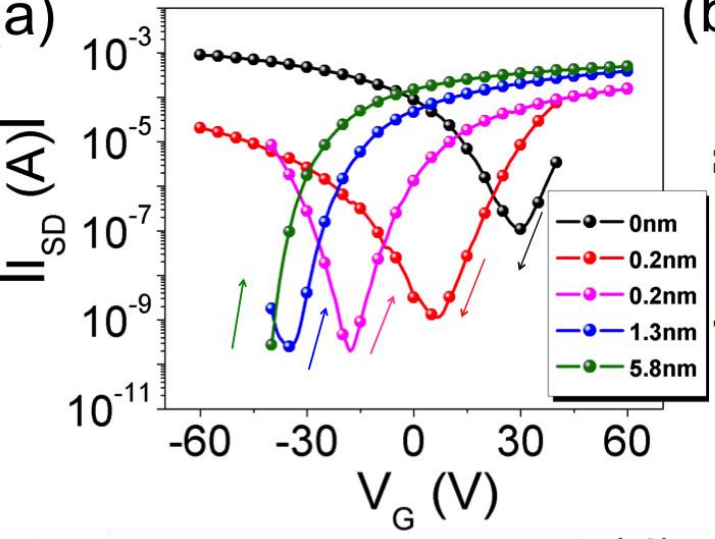

(c)

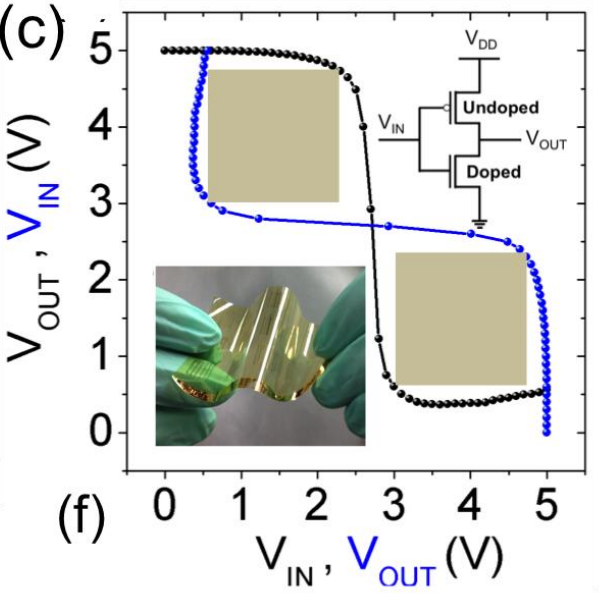

(d)
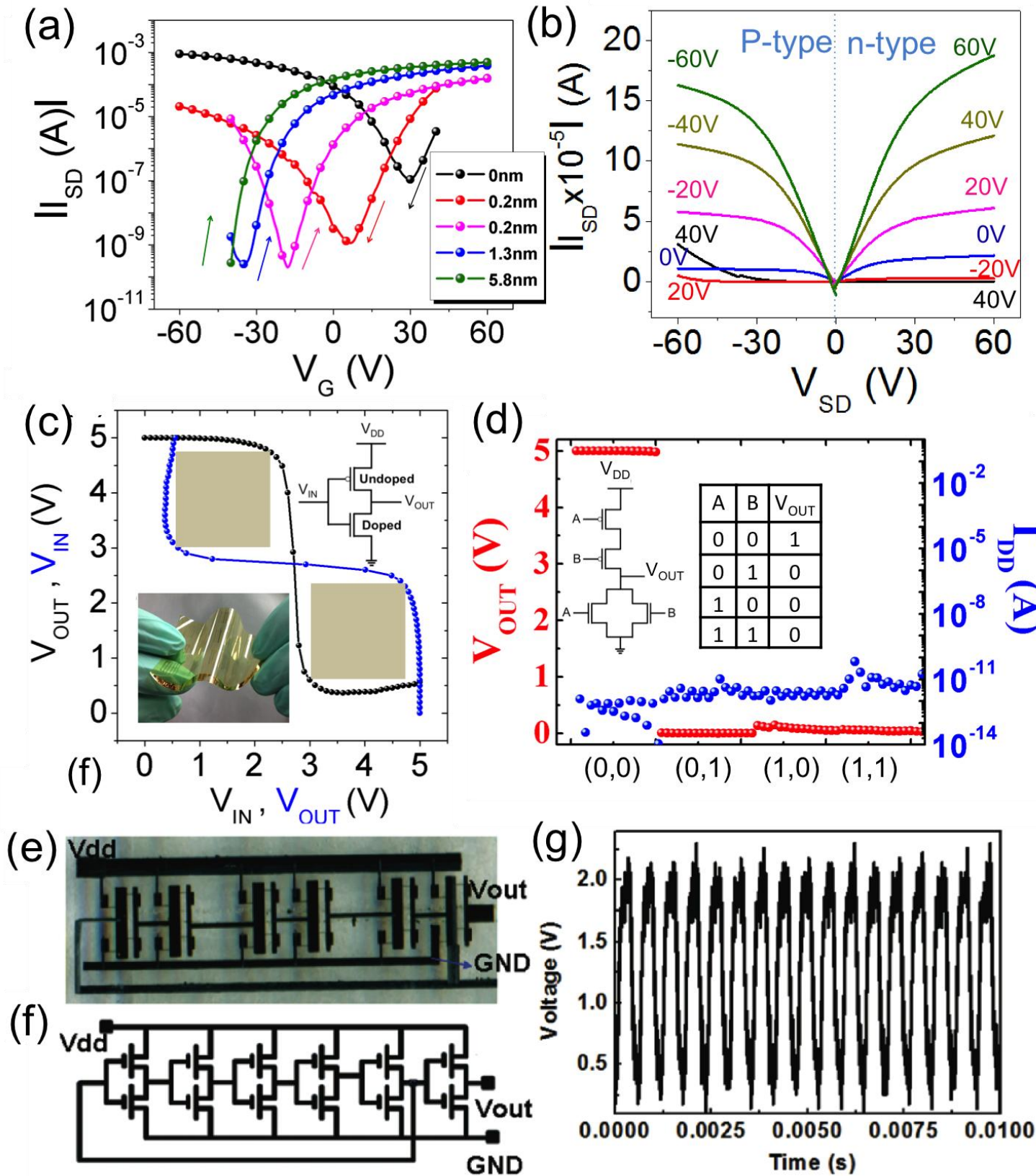

Figure 10 Polymer-sorted SWNT transistors for flexible logic circuits. (a) Transfer characteristics of SWNT transistor doped with o-MeO-DMBI-I at various nominal thicknesses, as determined using a quartz crystal monitor during deposition $\left(\mathrm{V}_{\mathrm{SD}}=80 \mathrm{~V}\right.$ for n-type and $\mathrm{V}_{\mathrm{SD}}=-80 \mathrm{~V}$ for p-type). [161] (b) Output characteristics of the undoped and n-doped SWNT transistors at an o-MeO-DMBI-I thickness of $5.8 \mathrm{~nm}$. [161] (c) Voltage transfer characteristics (VTC) and noise margin extraction of o-MeODMBI-I-doped flexible SWNT complementary inverters at $\mathrm{V}_{\mathrm{DD}}=5 \mathrm{~V}$. The insets show a digital photograph of a carbon nanotube circuit fabricated on a flexible polyimide substrate and the circuit diagram of the inverter. [161] (d) Flexible CMOS NOR logic gates at $V_{D D}=5 \mathrm{~V}$. The insets show the circuit diagram and the truth table for the logic gates. [161] (e) Photograph of a printed five-stage SWNT oscillator on a PET substrate. [147] (f) Circuit diagram of the printed oscillator. [147] (g) Output characteristics of the printed oscillator with a $1.7 \mathrm{kHz}$ oscillator frequency at $\mathrm{V}_{\mathrm{DD}}=2 \mathrm{~V}$. [147] Reprinted with permission from ref. 161, 147. Copyright 2014 National Academy of Sciences, Copyright 2014 Royal Society of Chemistry. 


\subsection{Infrared photodetectors}

SWNTs are promising materials for infrared (IR) photodetectors for telecommunications or imaging sensor applications because of their strong absorption in the IR $\left(>10^{5} \mathrm{~cm}^{-1}\right)$.[25] Polymer-sorted semiconducting SWNTs are especially beneficial because metallic SWNTs can quench excitons. [162] We used a transistor configuration with polymer-sorted SWNTs as the active channel and with a coating of $\mathrm{C}_{60}$ to enhance the exciton dissociation process (Figure 11a).[163] This transistor configuration allows for the tuning of the responsivity (photocurrent generated per incident light power) and the light-to-dark current ratio through the application of a gate voltage (Figure 11b). We achieved a maximum responsivity of $97.5 \mathrm{~A} \mathrm{~W}^{-1}$ at $\mathrm{V}_{\mathrm{G}}=-2 \mathrm{~V}$ and a maximum light-to-dark current ratio at 23 at $\mathrm{V}_{\mathrm{G}}=20 \mathrm{~V}$ (a responsivity of $19.4 \mathrm{~A} \mathrm{~W}^{-1}$ ). In addition, a specific detectivity (responsivity over noise current) of $1.17 \times 10^{9} \mathrm{~cm} \mathrm{~Hz}^{-1 / 2} \mathrm{~W}^{-1}$ was obtained at $1 \mathrm{kHz}$. Both of these values are among the highest ever attained for SWNT IR photodetectors.[163] Finally, we fabricated the devices on flexible substrates and demonstrated their electrical stability upon bending to a radius of $2 \mathrm{~mm}$ (Figure 11c). A linear array of such photodetectors was also demonstrated (Figure 11d).[163] 

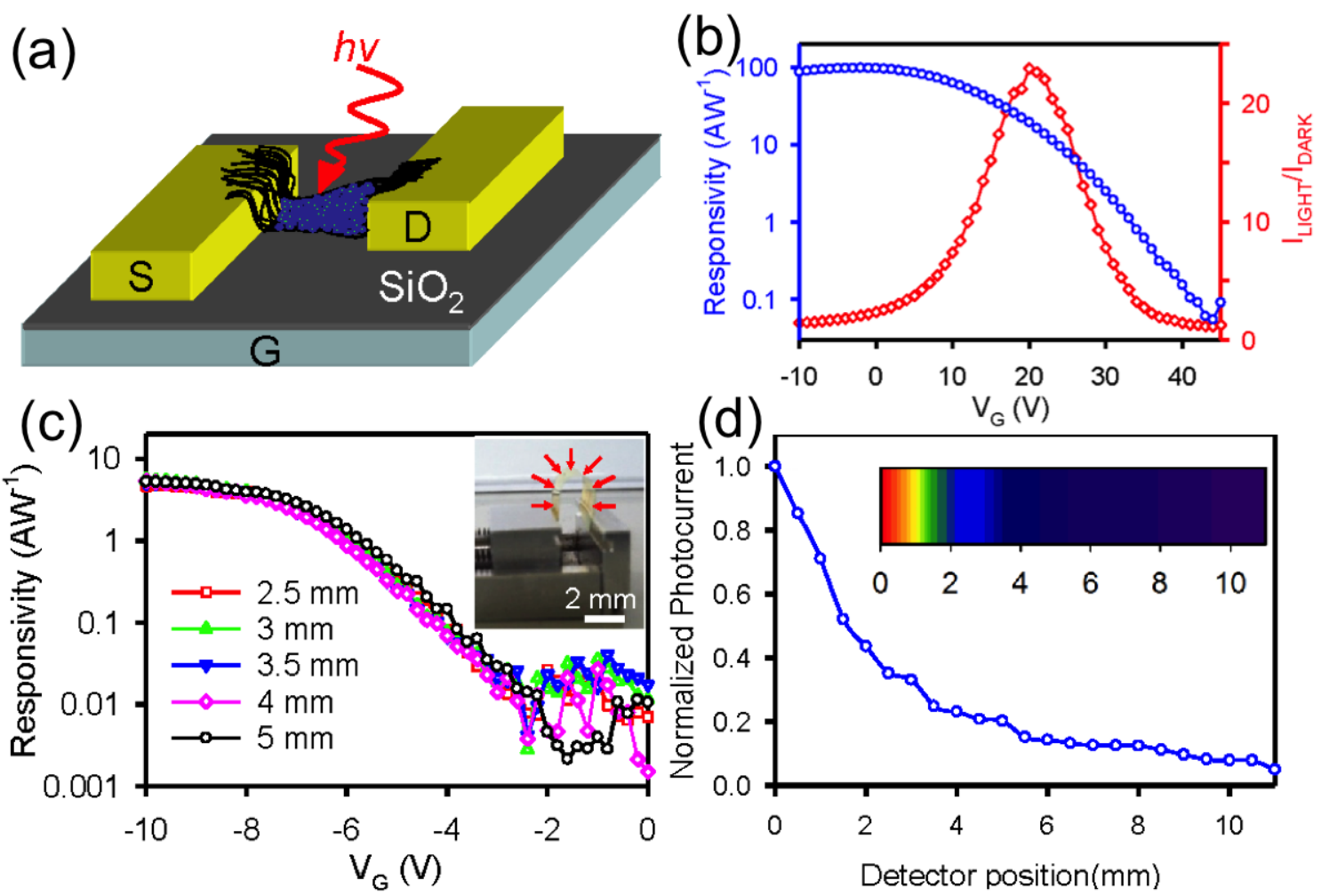

Figure 11 Polymer-sorted SWNTs for high-performance photodetectors. (a) Schematic diagram of an SWNT/C 60 photodetector. [163] (b) Responsivity (red circles) and light-to-dark current ratio (blue diamonds) as functions of gate voltage. [163] (c) Responsivity vs. gate voltage of a flexible SWNT/C 60 phototransistor under bending radii of down to $2 \mathrm{~mm}$. The inset is a photograph of a flexible phototransistor under bending. [163] (d) Plot of the normalized photocurrent of a 1D array of SWNT photodetectors with an infrared LED placed on the left end of the array. The spacing between the two photodetectors was $500 \mu \mathrm{m}$. The inset is a pixilation plot in which each pixel represents one photodetector in the array. Red represents the highest intensity, and dark blue represents the lowest intensity. [163] Reprinted with permission from ref. 163. Copyright 2015 Wiley Online Library.

\subsection{Absorbing layers for solar cells}

The strong optical absorptivity, excellent charge transport property and high stability of SWNTs enable them to be a potential candidate for active layers in solar cells. Bindl et al. utilized PFO-sorted SWNTs as a absorber and donor in combination $\mathrm{C}_{60}$ as a acceptor for bilayer solar cells (Figure 12a, b).[164] These heterojunction devices based on PFO-sorted semiconducting SWNT devices and $\mathrm{C}_{60}$ were highly rectifying and exhibited an on/off current of $\sim 10^{3}$ at $\pm 1 \mathrm{~V}$. These characteristics are typical of a type II heterojunction, at which the band offsets created barriers for both electrons and 
holes at the heterojunction interface. By contrast, the devices with unsorted SWNTs (dispersed in chlorobenzene) and $\mathrm{C}_{60}$ were poorly rectifying because of the presence of metallic SWNTs in the devices. The polymer-sorted SWNT devices also demonstrated an excellent external quantum efficiency (EQE, defined as the charge collected by the solar cell per incident photon) of up to $12.9 \pm$ 1.3\%, whereas the unsorted SWNT devices exhibited an EQE of less than 2.5\%. The lower EQE of the unsorted SWNT devices can be attributed to the presence of metallic SWNTs in the specimen, quenching the optically generated excitons and serving as free carrier recombination sites. Bindl et al. found that they could approach $100 \%$ internal quantum efficiency (IQE, defined as the charge collected by the solar cell per absorbed photon) using a small SWNT diameter $(<1 \mathrm{~nm})$ and a low thickness. They attributed the reduced IQE of the larger-diameter SWNTs to the reduced driving force for exciton dissociation. The IQE decreased at higher SWNT film thicknesses because it was more difficult for the generated excitons to migrate away from the $\mathrm{SWNT} / \mathrm{C}_{60}$ interface to dissociate into free charge carriers. With further optimization of the SWNT thickness and the $\mathrm{C}_{60}$ thickness, a solar cell power conversion efficiency of over $1 \%$ and an EQE of $43 \%$ at $1055 \mathrm{~nm}$ were demonstrated.[165] The thickness of the polymer-sorted SWNTs can also be controlled with nanoscale precision and low surface roughness by printing technology.[166] 
(a)

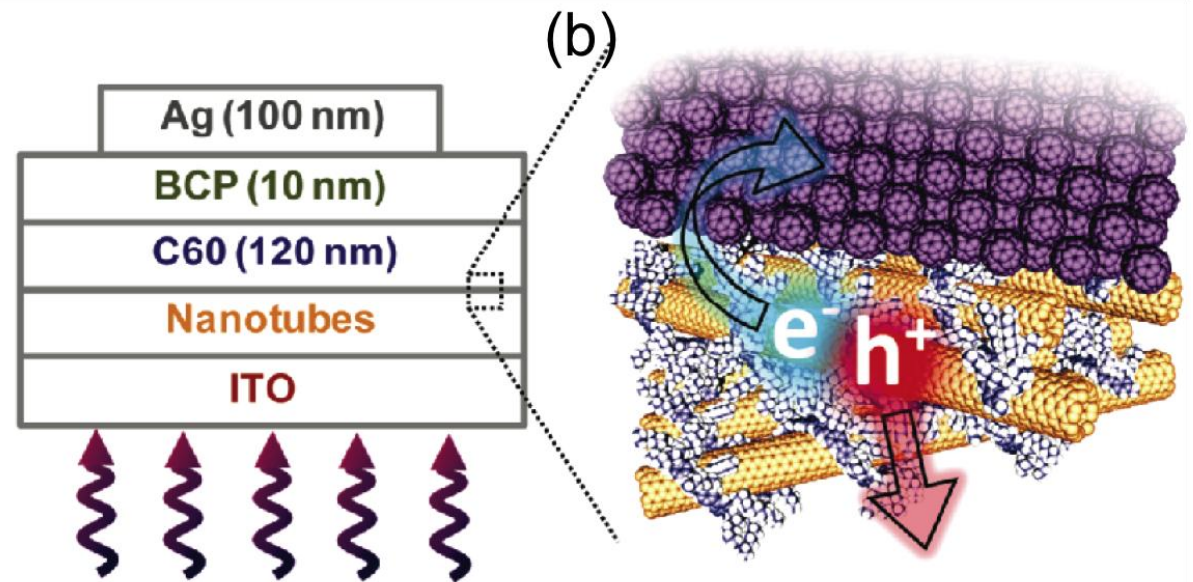

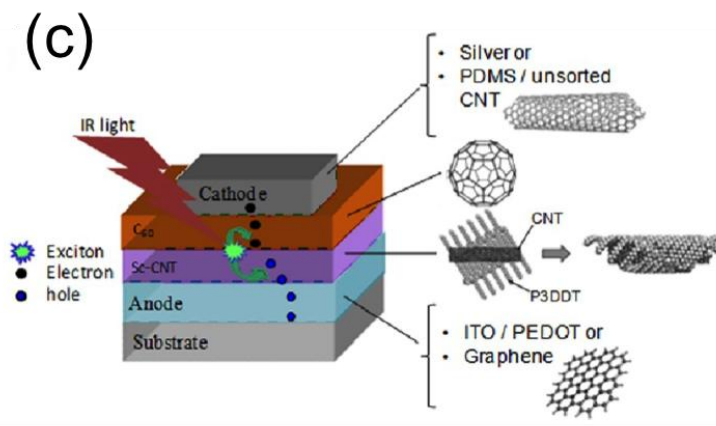

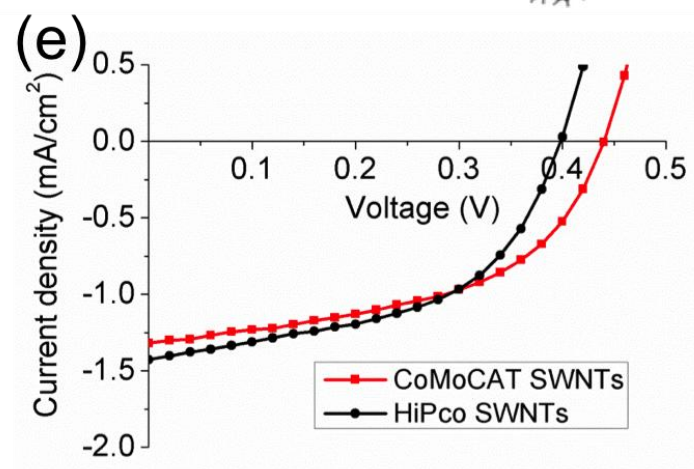

(d)
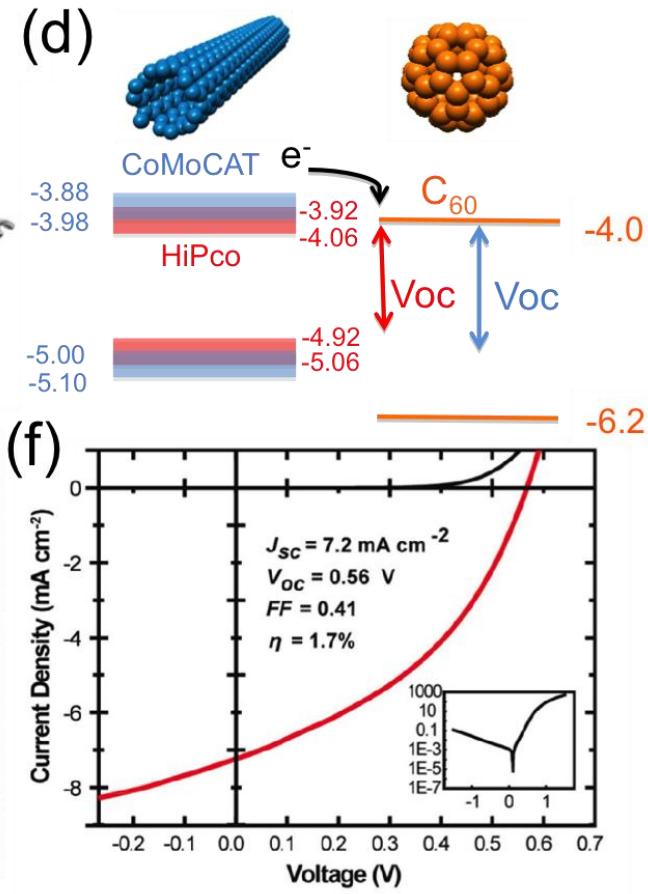

Figure 12 Polymer-sorted SWNTs as active layer for solar cell applications. (a) Device architecture of a polymer-sorted SWNT/C 60 solar cell. [164] (b) Schematic diagram showing the charge transfer at the nanotube $/ \mathrm{C}_{60}$ interface. [164] (c) Structure of an all-carbon solar cell, with ITO/PEDOT or rGO as the anode and Ag or n-type-doped SWNTs as the cathode. [167] (d) Schematic diagram showing the band structure and predicted open-circuit voltage and charge transfer of the SWNT/C 60 heterojunction. [64] (e) Current density-voltage characteristics of devices measured under simulated AM1.5 solar illumination for CoMoCAT SWNTs and HiPco SWNTs dispersed using P3DDT. [64] (f) Current density-voltage curves for an optimized SWNT aerogel solar cell in the dark (black) and under simulated AM1.5 solar illumination (red). Inset: dark current density-voltage characteristics on a logarithmic scale. [168] Reprinted with permission from ref. 164, 167, 64, 168. Copyright 2010 American Chemical Society, Copyright 2012 American Chemical Society, Copyright 2014 American Chemical Society, Copyright 2014 Wiley Online Library. 
We investigated the effects of the processing conditions on solar cell performance for P3DDT-sorted HiPco SWNTs. [167]We found that the use of both more highly concentrated solutions and multiple spin-coated layers can improve the short-circuit current $\left(\mathrm{J}_{\mathrm{sc}}\right)$. These improvements result from the increased absorption provided by the thicker SWNT layers. As a result, we achieved a power conversion efficiency of $0.46 \%$ under AM1.5 solar illumination. [167] In addition, we replaced the solar cell electrodes with rGO as the anode and n-doped SWNTs as the cathode for all carbon solar cells (Figure 12c). [167]The open-circuit voltage of the solar cells could be improved further by employing P3DDT-sorted small-diameter (6,5)-enriched CoMoCAT SWNTs as the active absorbing material (Figure 12d, e). [64]The improved open circuit voltage and EQE observed for these CoMoCAT SWNTs can be attributed to their better charge separation in comparison with the smallerband-gap HiPco SWNTs. [64]Recently, the Arnold group reported solar cells with a power conversion efficiency of 1.7\% (Figure 12f) based on bulk heterojunction (BHJ) morphologies between sortedSWNT aerogels and [6,6]-phenyl- $\mathrm{C}_{71}$-butyric acid methyl ester ( $\left.\mathrm{PC}_{71} \mathrm{BM}\right) \cdot[168]$

\subsection{D electronics}

One important benefit of SWNTs in comparison with other organic semiconductors used for flexible electronics is their stability at high temperatures. We exploited this advantage of SWNTs to fabricate a 3-dimensional (3D) structure of SWNT-based electronics using shape-memory polymers.[15] Freestanding 3D structures, such as boxes and flowers, can be fabricated in a programmable manner via the temperature-assisted shape control of a bilayer system (Figure 13a). In particular, the shape control process can be achieved using pre-patterned heaters, an approach that is suitable for forming 3D structures in an enclosed environment. Various P3DDT-sorted SWNT transistors, gas sensors, temperature sensors and memory devices were demonstrated and self-wrapped into irregularly shaped objects (Figure 13a) without any degradation in device performance (Figure 13b-d). [15] 
(c)
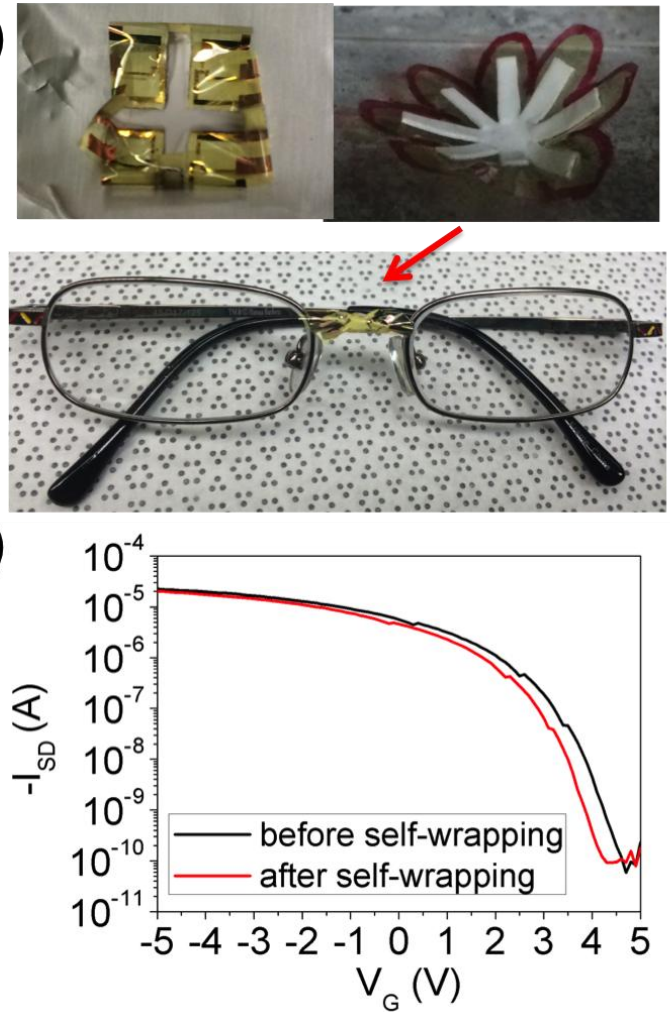

(b)

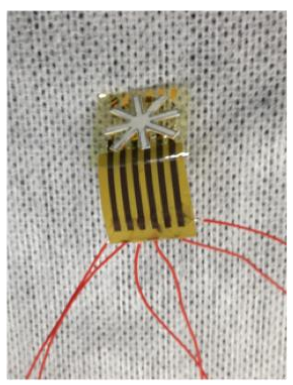

before

self-wrapping

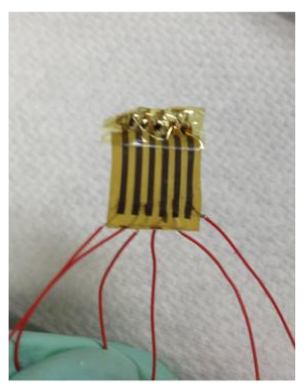

after

self-wrapping (d)

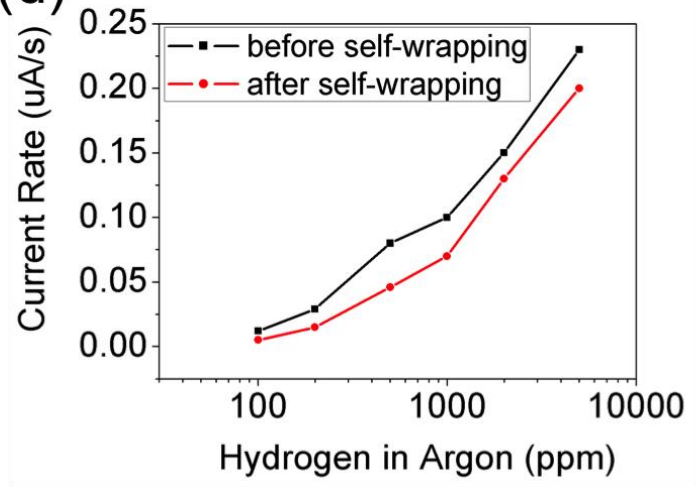

Figure 13 Shape-controlled, self-wrapped SWNT electronics. (a) Various 3D shaped objects (box, flowers) and a self-wrapped device (indicated by the red arrow) on eye glasses.[15] (b) Image of an SWNT transistor before and after the self-wrapping process. [15] (c) The transfer characteristics of an SWNT transistor before and after the self-wrapping process. [15] (d) A plot of the current rising rate vs. the hydrogen concentration before and after the self-wrapping process for a palladiumdecorated SWNT hydrogen sensor. [15] Reprinted with permission from ref. 15. Copyright 2015 Wiley Online Library.

\section{Outlook}

In this review, we summarized various parameters that affect conjugated-polymer-based sorting of semiconducting SWNTs and the applications of such sorted SWNTs in transistors, logic circuits, sensors and solar cells. Significant progress has been made in improving both the selectivity and the sorting yield of semiconducting SWNTs. Various devices fabricated using polymer-sorted semiconducting SWNTs all demonstrate state-of-the-art performance. We wish to highlight several future research directions regarding these topics: 
Sorting characterization methods: Currently, the selectivity and sorting yield of SWNTs are characterized predominantly via absorption spectroscopy. However, it is difficult to obtain a quantitative purity of semiconducting SWNTs using absorption spectroscopy.[169] Ideally, electrical measurements of individual SWNT devices will provide more quantitative and more accurate characterization on the percentage of semiconducting SWNTs in the sorted tubes. However, this process is extremely laborious. Therefore, better techniques must be developed to more efficiently determine the purity of semiconducting SWNTs. These non-electronic techniques might include dielectric force microscopy, $[95,170,171]$ scanning electron microscopy, [172]Raman spectroscopy[173, 174] or optical imaging/spectroscopy.[175] In addition, absorption spectroscopy can be used to quantify the relative yields of sorted SWNTs at various sorting conditions. However, this process is not a direct means to provide accurate yield of sorted SWNTs. Weighing the SWNTs before and after the sorting process is a better approach, but this process requires the complete removal of the polymers, a task that is both laborious and difficult to achieve. Recently, polymers that can both sort semiconducting SWNTs and easily disassemble after the sorting process have been demonstrated. [176-179] The development of improved characterization methods will simplify the screening for the optimal polymer and optimal conditions for the sorting of SWNTs.

Understanding the mechanism of polymer sorting: Understanding the mechanism of the sorting of SWNTs using conjugated polymers remains a challenge. In this review, we proposed a mechanism to explain how a conjugated polymer can sort semiconducting SWNTs based on current knowledge from observations to date. However, the exact mechanism remains unclear. Although simulations can assist in understanding the interactions of various types of polymers and SWNTs, experimental methods need to be developed to characterize the wrapping conformations of polymers and SWNTs as well as the charge transfer between them. With a clear understanding of the mechanism, we will be able not only to produce sorted semiconducting SWNTs with high yields and high purities but also to select for SWNTs with any specific chirality using custom-designed polymers. 
Electronic applications: For the applications of SWNTs in electronic devices, transistors with high mobilities, high on/off ratios, controlled threshold voltages and high bias stability have been demonstrated. However, further improvement of the mobility of SWNT network is still needed without compromising the device on/off ratio. Strategies for improving the mobility of SWNT transistors include (1) reducing the contact resistance between the SWNTs and the electrodes and (2) completely removal of the polymers after the dispersion of the SWNTs or using self-releasing sorting polymers. Since most n-doped SWNT devices are unstable in air, better encapsulation methods must be developed to achieve the long-term stability of n-type SWNT devices. For the application of SWNTs in solar cells, using small-diameter SWNTs, optimizing the layer thickness and applying bulk heterojunctions are all demonstrated as good strategies for improving the device performance. Higher efficiencies might be achieved by fabricating tandem cells with SWNTs of different diameters to absorb different wavelengths of light. Finally, the possibility of adding sorted SWNTs into other types of electronic devices (e.g., organic devices) to improve the performances of these devices should be explored.[180, 181]

Novel applications: Stretchable and flexible SWNT electronics are particularly promising for future wearable electronics and neural interface devices. The fabrication of SWNT 3D electronics is an emerging area and could be uniquely suited for conformal bioelectronics applications such as the electrical recording of cell potentials[182] or the sensing of health conditions.[183] In this context, several additional aspects need to be considered to better interface with bio-environments: (1) the mechanical and biological compatibility of SWNT electronics with cells, (2) their shape actuation in suitable temperature ranges, and (3) the requirements for stable device performance in bioenvironments. It will also be desirable to achieve the reversible shape control of these 3D electronics under various stimuli (e.g., light or pH). 
Acknowledgements

This work was funded by National Science Foundation (ECCS Award No. 1059020). H.W. acknowledges financial support from Link Foundation Energy Fellowship.

\section{References:}

[1] S. Iijima, Nature, 354 (1991) 56-58.

[2] S.J. Tans, A.R.M. Verschueren, C. Dekker, Nature, 393 (1998) 49-52.

[3] R. Martel, T. Schmidt, H.R. Shea, T. Hertel, P. Avouris, Applied Physics Letters, 73 (1998) 2447-2449.

[4] H. Dai, Accounts of Chemical Research, 35 (2002) 1035-1044.

[5] M.F.L. De Volder, S.H. Tawfick, R.H. Baughman, A.J. Hart, Science, 339 (2013) 535-539.

[6] L. Hu, D.S. Hecht, G. Grüner, Chemical Reviews, 110 (2010) 5790-5844. [7] P. Avouris, Z. Chen, V. Perebeinos, Nature Nanotechnology, 2 (2007) 605615.

[8] T. Dürkop, S.A. Getty, E. Cobas, M.S. Fuhrer, Nano Letters, 4 (2003) 35-39.

[9] H. Wang, J. Luo, A. Robertson, Y. Ito, W. Yan, V. Lang, M. Zaka, F. Schäffel, M.H. Rümmeli, G.A.D. Briggs, J.H. Warner, ACS Nano, 4 (2010) 6659-6664. [10] J.A. Rogers, T. Someya, Y. Huang, Science, 327 (2010) 1603-1607. [11] T. Sekitani, Y. Noguchi, K. Hata, T. Fukushima, T. Aida, T. Someya, Science, 321 (2008) 1468-1472.

[12] D.J. Lipomi, M. Vosgueritchian, B.C.K. Tee, S.L. Hellstrom, J.A. Lee, C.H. Fox, Z. Bao, Nature Nanotechnology, 6 (2011) 788-792.

[13] S. Park, M. Vosguerichian, Z. Bao, Nanoscale, 5 (2013) 1727-1752.

[14] S.H. Chae, W.J. Yu, J.J. Bae, D.L. Duong, D. Perello, H.Y. Jeong, Q.H. Ta, T.H. Ly, Q.A. Vu, M. Yun, X. Duan, Y.H. Lee, Nat Mater, 12 (2013) 403-409.

[15] H. Wang, Y. Wang, B.C.K. Tee, K. Kim, J. Lopez, W. Cai, Z. Bao, Advanced Science, (2015) n/a-n/a.

[16] P.H. Lau, K. Takei, C. Wang, Y. Ju, J. Kim, Z. Yu, T. Takahashi, G. Cho, A. Javey, Nano Letters, 13 (2013) 3864-3869.

[17] J. Minhun, K. Jaeyoung, N. Jinsoo, L. Namsoo, L. Chaemin, L. Gwangyong, K. Junseok, K. Hwiwon, J. Kyunghwan, A.D. Leonard, J.M. Tour, C. Gyoujin, Electron Devices, IEEE Transactions on, 57 (2010) 571-580.

[18] M. Ha, Y. Xia, A.A. Green, W. Zhang, M.J. Renn, C.H. Kim, M.C. Hersam, C.D. Frisbie, ACS Nano, 4 (2010) 4388-4395.

[19] E.B. Secor, M.C. Hersam, Journal of Physical Chemistry Letters, 6 (2015) 620-626.

[20] C. Wang, K. Takei, T. Takahashi, A. Javey, Chemical Society Reviews, 42 (2013) 2592-2609.

[21] Q. Cao, J.A. Rogers, Advanced Materials, 21 (2009) 29-53.

[22] G.S. Tulevski, A.D. Franklin, D. Frank, J.M. Lobez, Q. Cao, H. Park, A. Afzali, S.-J. Han, J.B. Hannon, W. Haensch, ACS Nano, 8 (2014) 8730-8745. 
[23] Q. Cao, S.-j. Han, Nanoscale, 5 (2013) 8852-8863.

[24] D.-M. Sun, C. Liu, W.-C. Ren, H.-M. Cheng, Small, 9 (2013) 1188-1205.

[25] P. Avouris, M. Freitag, V. Perebeinos, Nature Photonics, 2 (2008) 341-350.

[26] L.-M. Peng, Z. Zhang, S. Wang, Materials Today, 17 (2014) 433-442.

[27] Z. Jana, Semiconductor Science and Technology, 30 (2015) 074001.

[28] D.R. Kauffman, A. Star, Chemical Society Reviews, 37 (2008) 1197-1206.

[29] D.R. Kauffman, A. Star, Angewandte Chemie International Edition, 47

(2008) 6550-6570.

[30] W. Yang, K.R. Ratinac, S.P. Ringer, P. Thordarson, J.J. Gooding, F. Braet, Angewandte Chemie International Edition, 49 (2010) 2114-2138.

[31] J.M. Schnorr, T.M. Swager, Chemistry of Materials, 23 (2011) 646-657.

[32] Y. Che, H. Chen, H. Gui, J. Liu, B. Liu, C. Zhou, Semiconductor Science and

Technology, 29 (2014).

[33] C. Wang, D. Hwang, Z. Yu, K. Takei, J. Park, T. Chen, B. Ma, A. Javey, Nature Materials, 12 (2013) 899-904.

[34] M.M. Shulaker, G. Hills, N. Patil, H. Wei, H.-Y. Chen, H.S.P. Wong, S. Mitra, Nature, 501 (2013) 526-530.

[35] T. Guo, P. Nikolaev, A. Thess, D.T. Colbert, R.E. Smalley, Chemical Physics Letters, 243 (1995) 49-54.

[36] M. José - Yacamán, M. Miki - Yoshida, L. Rendón, J.G. Santiesteban, Applied Physics Letters, 62 (1993) 202-204.

[37] P. Nikolaev, M.J. Bronikowski, R.K. Bradley, F. Rohmund, D.T. Colbert, K.A. Smith, R.E. Smalley, Chemical Physics Letters, 313 (1999) 91-97.

[38] B. Kitiyanan, W.E. Alvarez, J.H. Harwell, D.E. Resasco, Chemical Physics Letters, 317 (2000) 497-503.

[39] M.C. Hersam, Nature Nanotechnology, 3 (2008) 387-394.

[40] C.-H. Liu, H.-L. Zhang, Nanoscale, 2 (2010) 1901-1918.

[41] Z. Liu, L. Jiao, Y. Yao, X. Xian, J. Zhang, Advanced Materials, 22 (2010) 2285-2310.

[42] J. Liu, M.C. Hersam, MRS Bulletin, 35 (2010) 315-321.

[43] H. Zhang, B. Wu, W. Hu, Y. Liu, Chemical Society Reviews, 40 (2011) 13241336.

[44] M. Zheng, A. Jagota, E.D. Semke, B.A. Diner, R.S. McLean, S.R. Lustig, R.E. Richardson, N.G. Tassi, Nature Materials, 2 (2003) 338-342.

[45] M. Zheng, A. Jagota, M.S. Strano, A.P. Santos, P. Barone, S.G. Chou, B.A.

Diner, M.S. Dresselhaus, R.S. McLean, G.B. Onoa, G.G. Samsonidze, E.D. Semke, M. Usrey, D.J. Walls, Science, 302 (2003) 1545-1548.

[46] M.S. Arnold, A.A. Green, J.F. Hulvat, S.I. Stupp, M.C. Hersam, Nat Nano, 1 (2006) 60-65.

[47] T. Tanaka, H. Jin, Y. Miyata, S. Fujii, H. Suga, Y. Naitoh, T. Minari, T. Miyadera, K. Tsukagoshi, H. Kataura, Nano Letters, 9 (2009) 1497-1500. [48] A. Nish, J.-Y. Hwang, J. Doig, R.J. Nicholas, Nature Nanotechnology, 2 (2007) 640-646. 
[49] H.W. Lee, Y. Yoon, S. Park, J.H. Oh, S. Hong, L.S. Liyanage, H. Wang, S. Morishita, N. Patil, Y.J. Park, J.J. Park, A. Spakowitz, G. Galli, F. Gygi, P.H.S. Wong, J.B.H. Tok, J.M. Kim, Z. Bao, Nat Commun, 2 (2011) 541.

[50] P.G. Collins, M.S. Arnold, P. Avouris, Science, 292 (2001) 706-709.

[51] S.H. Jin, S.N. Dunham, J. Song, X. Xie, J.H. Kim, C. Lu, A. Islam, F. Du, J. Kim, J. Felts, Y. Li, F. Xiong, M.A. Wahab, M. Menon, E. Cho, K.L. Grosse, D.J. Lee, H.U. Chung, E. Pop, M.A. Alam, W.P. King, Y. Huang, J.A. Rogers, Nature Nanotechnology, 8 (2013) 347-355.

[52] X. Xie, S.H. Jin, M.A. Wahab, A.E. Islam, C. Zhang, F. Du, E. Seabron, T. Lu, S.N. Dunham, H.I. Cheong, Y.-C. Tu, Z. Guo, H.U. Chung, Y. Li, Y. Liu, J.-H. Lee, J. Song, Y. Huang, M.A. Alam, W.L. Wilson, J.A. Rogers, Nat Commun, 5 (2014). [53] M.C. LeMieux, M. Roberts, S. Barman, Y.W. Jin, J.M. Kim, Z.N. Bao, Science, 321 (2008) 101-104.

[54] G. Hong, M. Zhou, R. Zhang, S. Hou, W. Choi, Y.S. Woo, J.-Y. Choi, Z. Liu, J. Zhang, Angewandte Chemie International Edition, 50 (2011) 6819-6823. [55] M.S. Strano, C.A. Dyke, M.L. Usrey, P.W. Barone, M.J. Allen, H. Shan, C. Kittrell, R.H. Hauge, J.M. Tour, R.E. Smalley, Science, 301 (2003) 1519-1522. [56] M. Kanungo, H. Lu, G.G. Malliaras, G.B. Blanchet, Science, 323 (2009) 234237.

[57] X. Tu, S. Manohar, A. Jagota, M. Zheng, Nature, 460 (2009) 250-253. [58] S. Ghosh, S.M. Bachilo, R.B. Weisman, Nature Nanotechnology, 5 (2010) 443-450.

[59] H. Liu, D. Nishide, T. Tanaka, H. Kataura, Nature Communications, 2 (2011).

[60] C.Y. Khripin, J.A. Fagan, M. Zheng, Journal of the American Chemical Society, 135 (2013) 6822-6825.

[61] J.A. Fagan, C.Y. Khripin, C.A. Silvera Batista, J.R. Simpson, E.H. Hároz, A.R. Hight Walker, M. Zheng, Advanced Materials, 26 (2014) 2800-2804. [62] S.K. Samanta, M. Fritsch, U. Scherf, W. Gomulya, S.Z. Bisri, M.A. Loi, Accounts of Chemical Research, 47 (2014) 2446-2456.

[63] S. Park, H.W. Lee, H. Wang, S. Selvarasah, M.R. Dokmeci, Y.J. Park, S.N. Cha, J.M. Kim, Z. Bao, ACS Nano, 6 (2012) 2487-2496.

[64] H. Wang, G.I. Koleilat, P. Liu, G. Jiménez-Osés, Y.-C. Lai, M. Vosgueritchian, Y. Fang, S. Park, K.N. Houk, Z. Bao, ACS Nano, 8 (2014) 2609-2617.

[65] R.H. Friend, R.W. Gymer, A.B. Holmes, J.H. Burroughes, R.N. Marks, C. Taliani, D.D.C. Bradley, D.A. Dos Santos, J.L. Brédas, M. Lögdlund, W.R. Salaneck, Nature, 397 (1999) 121-128.

[66] A.C. Grimsdale, K.L. Chan, R.E. Martin, P.G. Jokisz, A.B. Holmes, Chemical Reviews, 109 (2009) 897-1091.

[67] J.H. Burroughes, D.D.C. Bradley, A.R. Brown, R.N. Marks, K. Mackay, R.H. Friend, P.L. Burns, A.B. Holmes, Nature, 347 (1990) 539-541.

[68] S. Günes, H. Neugebauer, N.S. Sariciftci, Chemical Reviews, 107 (2007) 1324-1338.

[69] G. Li, R. Zhu, Y. Yang, Nature Photonics, 6 (2012) 153-161.

[70] D. Wöhrle, D. Meissner, Advanced Materials, 3 (1991) 129-138.

[71] Z. Bao, J. Locklin, Organic field-effect transistors, CRC press2007. 
[72] A.R. Murphy, J.M.J. Fréchet, Chemical Reviews, 107 (2007) 1066-1096. [73] J. Mei, Y. Diao, A.L. Appleton, L. Fang, Z. Bao, Journal of the American Chemical Society, 135 (2013) 6724-6746.

[74] Z. Bao, A. Dodabalapur, A.J. Lovinger, Applied Physics Letters, 69 (1996) 4108-4110.

[75] S.W. Thomas Iii, G.D. Joly, T.M. Swager, Chemical Reviews, 107 (2007) 1339-1386.

[76] X. Feng, L. Liu, S. Wang, D. Zhu, Chemical Society Reviews, 39 (2010) 24112419.

[77] J.S. Yang, T.M. Swager, Journal of the American Chemical Society, 120 (1998) 11864-11873.

[78] J. Chen, H. Liu, W.A. Weimer, M.D. Halls, D.H. Waldeck, G.C. Walker, Journal of the American Chemical Society, 124 (2002) 9034-9035.

[79] D. Tuncel, Nanoscale, 3 (2011) 3545-3554.

[80] H. Ozawa, N. Ide, T. Fujigaya, Y. Niidome, N. Nakashima, Chemistry Letters, 40 (2011) 239-241.

[81] K. Akazaki, F. Toshimitsu, H. Ozawa, T. Fujigaya, N. Nakashima, Journal of the American Chemical Society, 134 (2012) 12700-12707.

[82] P. Deria, C.D. Von Bargen, J.-H. Olivier, A.S. Kumbhar, J.G. Saven, M.J.

Therien, Journal of the American Chemical Society, 135 (2013) 16220-16234.

[83] M. Tange, T. Okazaki, S. Iijima, ACS Applied Materials and Interfaces, 4 (2012) 6458-6462.

[84] M. Tange, T. Okazaki, S. Iijima, Journal of the American Chemical Society, 133 (2011) 11908-11911.

[85] F. Chen, B. Wang, Y. Chen, L.-J. Li, Nano Letters, 7 (2007) 3013-3017.

[86] F. Hennrich, S. Lebedkin, M.M. Kappes, physica status solidi (b), 245 (2008) 1951-1953.

[87] F. Jakubka, S.P. SchießI, S. Martin, J.M. Englert, F. Hauke, A. Hirsch, J.

Zaumseil, ACS Macro Letters, 1 (2012) 815-819.

[88] H. Ozawa, T. Fujigaya, Y. Niidome, N. Nakashima, Chemistry - An Asian Journal, 6 (2011) 3281-3285.

[89] N. Stürzl, F. Hennrich, S. Lebedkin, M.M. Kappes, The Journal of Physical Chemistry C, 113 (2009) 14628-14632.

[90] F.A. Lemasson, T. Strunk, P. Gerstel, F. Hennrich, S. Lebedkin, C. BarnerKowollik, W. Wenzel, M.M. Kappes, M. Mayor, Journal of the American Chemical Society, 133 (2010) 652-655.

[91] H. Ozawa, T. Fujigaya, Y. Niidome, N. Hotta, M. Fujiki, N. Nakashima, Journal of the American Chemical Society, 133 (2011) 2651-2657.

[92] J. Gao, M.A. Loi, E.J.F. de Carvalho, M.C. dos Santos, ACS Nano, 5 (2011) 3993-3999.

[93] R. Si, L. Wei, H. Wang, D. Su, S.H. Mushrif, Y. Chen, Chemistry - An Asian Journal, 9 (2014) 868-877.

[94] H. Li, F. Zhang, S. Qiu, N. Lv, Z. Zhao, Q. Li, Z. Cui, Chemical Communications, 49 (2013) 10492-10494.

[95] H. Wang, Y. Li, G. Jiménez-Osés, P. Liu, Y. Fang, J. Zhang, Y.-C. Lai, S. Park, L. Chen, K.N. Houk, Z. Bao, Advanced Functional Materials, 25 (2015) 1837-1844. 
[96] W. Yi, A. Malkovskiy, Q. Chu, A.P. Sokolov, M.L. Colon, M. Meador, Y. Pang, The Journal of Physical Chemistry B, 112 (2008) 12263-12269.

[97] W. Yi, A. Malkovskiy, Y. Xu, X.-Q. Wang, A.P. Sokolov, M. Lebron-Colon, M.A. Meador, Y. Pang, Polymer, 51 (2010) 475-481.

[98] F. Lemasson, J. Tittmann, F. Hennrich, N. Sturzl, S. Malik, M.M. Kappes, M. Mayor, Chemical Communications, 47 (2011) 7428-7430.

[99] F. Lemasson, N. Berton, J. Tittmann, F. Hennrich, M.M. Kappes, M. Mayor, Macromolecules, 45 (2012) 713-722.

[100] P. Imin, M. Imit, A. Adronov, Macromolecules, 45 (2012) 5045-5050.

[101] Y. Chen, A. Malkovskiy, X.-Q. Wang, M. Lebron-Colon, A.P. Sokolov, K.

Perry, K. More, Y. Pang, ACS Macro Letters, 1 (2012) 246-251.

[102] Y. Chen, Y. Xu, K. Perry, A.P. Sokolov, K. More, Y. Pang, ACS Macro Letters, 1 (2012) 701-705.

[103] Y. Chen, Y. Xu, Q. Wang, R.N. Gunasinghe, X.-Q. Wang, Y. Pang, Small, 9 (2013) 870-875.

[104] T. Fukumaru, F. Toshimitsu, T. Fujigaya, N. Nakashima, Nanoscale, 6 (2014) 5879-5886.

[105] N.A. Rice, A.V. Subrahmanyam, B.R. Coleman, A. Adronov, Macromolecules, 48 (2015) 5155-5161.

[106] K. Mulla, S. Liang, H. Shaik, E.A. Younes, A. Adronov, Y. Zhao, Chemical Communications, 51 (2015) 149-152.

[107] S. Liang, Y. Zhao, A. Adronov, Journal of the American Chemical Society, 136 (2014) 970-977.

[108] Y.K. Kang, O.-S. Lee, P. Deria, S.H. Kim, T.-H. Park, D.A. Bonnell, J.G. Saven, M.J. Therien, Nano Letters, 9 (2009) 1414-1418.

[109] P. Deria, L.E. Sinks, T.-H. Park, D.M. Tomezsko, M.J. Brukman, D.A.

Bonnell, M.J. Therien, Nano Letters, 10 (2010) 4192-4199.

[110] N. Berton, F. Lemasson, J. Tittmann, N. St $\sqrt{ }{ }^{\circ}$ rzl, F. Hennrich, M.M.

Kappes, M. Mayor, Chemistry of Materials, 23 (2011) 2237-2249.

[111] K.S. Mistry, B.A. Larsen, J.L. Blackburn, ACS Nano, 7 (2013) 2231-2239.

[112] N. Berton, F. Lemasson, A. Poschlad, V. Meded, F. Tristram, W. Wenzel, F.

Hennrich, M.M. Kappes, M. Mayor, Small, 10 (2014) 360-367.

[113] X. Zhou, J.-Y. Park, S. Huang, J. Liu, P.L. McEuen, Physical Review Letters, 95 (2005) 146805.

[114] Z. Chen, J. Appenzeller, J. Knoch, Y.-m. Lin, P. Avouris, Nano Letters, 5 (2005) 1497-1502.

[115] H. Wang, J. Mei, P. Liu, K. Schmidt, G. Jiménez-Osés, S. Osuna, L. Fang, C.J. Tassone, A.P. Zoombelt, A.N. Sokolov, K.N. Houk, M.F. Toney, Z. Bao, ACS Nano, 7 (2013) 2659-2668.

[116] W. Gomulya, G.D. Costanzo, E.J.F. De Carvalho, S.Z. Bisri, V. Derenskyi, M. Fritsch, N. Fröhlich, S. Allard, P. Gordiichuk, A. Herrmann, S.J. Marrink, M.C. Dos Santos, U. Scherf, M.A. Loi, Advanced Materials, 25 (2013) 2948-2956. [117] T. Lei, Y.-C. Lai, G. Hong, H. Wang, P. Hayoz, R.T. Weitz, C. Chen, H. Dai, Z. Bao, Small, 11 (2015) 2946-2954. 
[118] G.J. Brady, Y. Joo, M.-Y. Wu, M.J. Shea, P. Gopalan, M.S. Arnold, ACS Nano, 8 (2014) 11614-11621.

[119] J.-Y. Hwang, A. Nish, J. Doig, S. Douven, C.-W. Chen, L.-C. Chen, R.J.

Nicholas, Journal of the American Chemical Society, 130 (2008) 3543-3553. [120] H. Wang, B. Hsieh, G. Jiménez-Osés, P. Liu, C.J. Tassone, Y. Diao, T. Lei, K.N. Houk, Z. Bao, Small, 11 (2015) 126-133.

[121] J. Ding, Z. Li, J. Lefebvre, F. Cheng, G. Dubey, S. Zou, P. Finnie, A. Hrdina, L. Scoles, G.P. Lopinski, C.T. Kingston, B. Simard, P.R.L. Malenfant, Nanoscale, 6 (2014) 2328-2339.

[122] J. Han, Q. Ji, S. Qiu, H. Li, S. Zhang, H. Jin, Q. Li, Chemical Communications, 51 (2015) 4712-4714.

[123] W. Gomulya, J.M. Salazar Rios, V. Derenskyi, S.Z. Bisri, S. Jung, M. Fritsch, S. Allard, U. Scherf, M.C. dos Santos, M.A. Loi, Carbon, 84 (2015) 66-73.

[124] P. Imin, F. Cheng, A. Adronov, Polymer Chemistry, 2 (2011) 1404-1408. [125] S.P. Schießl, N. Fröhlich, M. Held, F. Gannott, M. Schweiger, M. Forster, U. Scherf, J. Zaumseil, ACS Applied Materials \& Interfaces, 7 (2015) 682-689. [126] N. Berton, F. Lemasson, F. Hennrich, M.M. Kappes, M. Mayor, Chemical Communications, 48 (2012) 2516-2518.

[127] Y. Kanai, J.C. Grossman, Nano Letters, 8 (2008) 908-912.

[128] J.L. Bahr, E.T. Mickelson, M.J. Bronikowski, R.E. Smalley, J.M. Tour, Chemical Communications, (2001) 193-194.

[129] C.W. Lee, X. Han, F. Chen, J. Wei, Y. Chen, M.B. Chan-Park, L.-J. Li, Advanced Materials, 22 (2010) 1278-1282.

[130] N. Rouhi, D. Jain, K. Zand, P.J. Burke, Advanced Materials, 23 (2011) 94 99.

[131] A.A. Green, M.C. Hersam, Advanced Materials, 23 (2011) 2185-2190. [132] N. Izard, S. Kazaoui, K. Hata, T. Okazaki, T. Saito, S. Iijima, N. Minami, Applied Physics Letters, 92 (2008) 243112.

[133] S.Z. Bisri, J. Gao, V. Derenskyi, W. Gomulya, I. Iezhokin, P. Gordiichuk, A. Herrmann, M.A. Loi, Advanced Materials, 24 (2012) 6147-6152.

[134] C. Wang, L. Qian, W. Xu, S. Nie, W. Gu, J. Zhang, J. Zhao, J. Lin, Z. Chen, Z. Cui, Nanoscale, 5 (2013) 4156-4161.

[135] L.S. Liyanage, H. Lee, N. Patil, S. Park, S. Mitra, Z. Bao, H.-S.P. Wong, ACS Nano, 6 (2012) 451-458.

[136] S. Park, G. Pitner, G. Giri, J.H. Koo, J. Park, K. Kim, H. Wang, R. Sinclair, H.S.P. Wong, Z. Bao, Advanced Materials, 27 (2015) 2656-2662.

[137] Y. Joo, G.J. Brady, M.S. Arnold, P. Gopalan, Langmuir, 30 (2014) 34603466.

[138] G.J. Brady, Y. Joo, S. Singha Roy, P. Gopalan, M.S. Arnold, Applied Physics Letters, 104 (2014) 083107.

[139] Q. Cao, S.-j. Han, G.S. Tulevski, Y. Zhu, D.D. Lu, W. Haensch, Nat Nano, 8 (2013) 180-186.

[140] J. Wu, L. Jiao, A. Antaris, C.L. Choi, L. Xie, Y. Wu, S. Diao, C. Chen, Y. Chen, H. Dai, Small, 9 (2013) 4142-4148.

[141] S.H. Jin, S.N. Dunham, J. Song, X. Xie, J.-h. Kim, C. Lu, A. Islam, F. Du, J. Kim, J. Felts, Y. Li, F. Xiong, M.A. Wahab, M. Menon, E. Cho, K.L. Grosse, D.J. Lee, H.U. 
Chung, E. Pop, M.A. Alam, W.P. King, Y. Huang, J.A. Rogers, Nat Nano, 8 (2013) 347-355.

[142] W. Kim, A. Javey, O. Vermesh, Q. Wang, Y. Li, H. Dai, Nano Letters, 3 (2003) 193-198.

[143] Z. Liu, H. Li, Z. Qiu, S.-L. Zhang, Z.-B. Zhang, Advanced Materials, 24 (2012) 3633-3638.

[144] S.H. Jin, A.E. Islam, T.-i. Kim, J.-h. Kim, M.A. Alam, J.A. Rogers, Advanced Functional Materials, 22 (2012) 2276-2284.

[145] H. Wang, B. Cobb, A. van Breemen, G. Gelinck, Z. Bao, Advanced Materials, 26 (2014) 4588-4593.

[146] Z. Liu, J. Zhao, W. Xu, L. Qian, S. Nie, Z. Cui, ACS Applied Materials \& Interfaces, 6 (2014) 9997-10004.

[147] W. Xu, Z. Liu, J. Zhao, W. Xu, W. Gu, X. Zhang, L. Qian, Z. Cui, Nanoscale, 6 (2014) 14891-14897.

[148] W.J. Yu, U.J. Kim, B.R. Kang, I.H. Lee, E.-H. Lee, Y.H. Lee, Nano Letters, 9

(2009) 1401-1405.

[149] F. Garnier, R. Hajlaoui, A. Yassar, P. Srivastava, Science, 265 (1994)

1684-1686.

[150] J.A. Rogers, Z. Bao, K. Baldwin, A. Dodabalapur, B. Crone, V.R. Raju, V.

Kuck, H. Katz, K. Amundson, J. Ewing, P. Drzaic, Proceedings of the National Academy of Sciences, 98 (2001) 4835-4840.

[151] L. Qian, W. Xu, X. Fan, C. Wang, J. Zhang, J. Zhao, Z. Cui, The Journal of Physical Chemistry C, 117 (2013) 18243-18250.

[152] W. Xu, J. Zhao, L. Qian, X. Han, L. Wu, W. Wu, M. Song, L. Zhou, W. Su, C. Wang, S. Nie, Z. Cui, Nanoscale, 6 (2014) 1589-1595.

[153] D.-H. Kim, N. Lu, R. Ma, Y.-S. Kim, R.-H. Kim, S. Wang, J. Wu, S.M. Won, H. Tao, A. Islam, K.J. Yu, T.-i. Kim, R. Chowdhury, M. Ying, L. Xu, M. Li, H.-J. Chung, H. Keum, M. McCormick, P. Liu, Y.-W. Zhang, F.G. Omenetto, Y. Huang, T. Coleman, J.A. Rogers, Science, 333 (2011) 838-843.

[154] S. Xu, Y. Zhang, L. Jia, K.E. Mathewson, K.-I. Jang, J. Kim, H. Fu, X. Huang, P. Chava, R. Wang, S. Bhole, L. Wang, Y.J. Na, Y. Guan, M. Flavin, Z. Han, Y. Huang, J.A. Rogers, Science, 344 (2014) 70-74.

[155] S.P. Lacour, S. Wagner, Z. Huang, Z. Suo, Applied Physics Letters, 82 (2003) 2404-2406.

[156] T. Sekitani, H. Nakajima, H. Maeda, T. Fukushima, T. Aida, K. Hata, T.

Someya, Nat Mater, 8 (2009) 494-499.

[157] M.-F. Yu, O. Lourie, M.J. Dyer, K. Moloni, T.F. Kelly, R.S. Ruoff, Science, 287 (2000) 637-640.

[158] F. Xu, M.Y. Wu, N.S. Safron, S.S. Roy, R.M. Jacobberger, D.J. Bindl, J.H. Seo,

T.H. Chang, Z. Ma, M.S. Arnold, Nano Letters, 14 (2014) 682-686.

[159] A. Chortos, G.I. Koleilat, R. Pfattner, D. Kong, P. Lin, R. Nur, T. Lei, H.

Wang, N. Liu, Y.-C. Lai, M.-G. Kim, J.W. Chung, S. Lee, Z. Bao, Advanced Materials, (2015) n/a-n/a.

[160] F. Bottacchi, L. Petti, F. Späth, I. Namal, G. Tröster, T. Hertel, T.D.

Anthopoulos, Applied Physics Letters, 106 (2015) 193302. 
[161] H. Wang, P. Wei, Y. Li, J. Han, H.R. Lee, B.D. Naab, N. Liu, C. Wang, E. Adijanto, B.C.-K. Tee, S. Morishita, Q. Li, Y. Gao, Y. Cui, Z. Bao, Proceedings of the National Academy of Sciences, 111 (2014) 4776-4781.

[162] M.S. Arnold, J.D. Zimmerman, C.K. Renshaw, X. Xu, R.R. Lunt, C.M. Austin, S.R. Forrest, Nano Letters, 9 (2009) 3354-3358.

[163] S. Park, S.J. Kim, J.H. Nam, G. Pitner, T.H. Lee, A.L. Ayzner, H. Wang, S.W. Fong, M. Vosgueritchian, Y.J. Park, M.L. Brongersma, Z. Bao, Advanced Materials, 27 (2015) 759-765.

[164] D.J. Bindl, M.-Y. Wu, F.C. Prehn, M.S. Arnold, Nano Letters, 11 (2010) 455460.

[165] M.J. Shea, M.S. Arnold, Applied Physics Letters, 102 (2013) 243101.

[166] S.L. Guillot, K.S. Mistry, A.D. Avery, J. Richard, A.-M. Dowgiallo, P.F.

Ndione, J. van de Lagemaat, M.O. Reese, J.L. Blackburn, Nanoscale, 7 (2015)

6556-6566.

[167] M.P. Ramuz, M. Vosgueritchian, P. Wei, C. Wang, Y. Gao, Y. Wu, Y. Chen, Z.

Bao, ACS Nano, 6 (2012) 10384-10395.

[168] Y. Ye, D.J. Bindl, R.M. Jacobberger, M.-Y. Wu, S.S. Roy, M.S. Arnold, Small, 10 (2014) 3299-3306.

[169] A.V. Naumov, S. Ghosh, D.A. Tsyboulski, S.M. Bachilo, R.B. Weisman, ACS Nano, 5 (2011) 1639-1648.

[170] W. Lu, Y. Xiong, A. Hassanien, W. Zhao, M. Zheng, L. Chen, Nano Letters, 9 (2009) 1668-1672.

[171] Y. Li, J. Ge, J. Cai, J. Zhang, W. Lu, J. Liu, L. Chen, Nano Research, 7 (2014) 1623-1630.

[172] J. Li, Y. He, Y. Han, K. Liu, J. Wang, Q. Li, S. Fan, K. Jiang, Nano Letters, 12 (2012) 4095-4101.

[173] P. Finnie, J. Ding, Z. Li, C.T. Kingston, The Journal of Physical Chemistry C, 118 (2014) 30127-30138.

[174] Z. Li, J. Ding, P. Finnie, J. Lefebvre, F. Cheng, C. Kingston, P.L. Malenfant, Nano Research, (2015) 1-9.

[175] K. Liu, X. Hong, Q. Zhou, C. Jin, J. Li, W. Zhou, J. Liu, E. Wang, A. Zettl, F.

Wang, Nat Nano, 8 (2013) 917-922.

[176] W.Z. Wang, W.F. Li, X.Y. Pan, C.M. Li, L.-J. Li, Y.G. Mu, J.A. Rogers, M.B.

Chan-Park, Advanced Functional Materials, 21 (2011) 1643-1651.

[177] I. Pochorovski, H. Wang, J.I. Feldblyum, X. Zhang, A.L. Antaris, Z. Bao,

Journal of the American Chemical Society, 137 (2015) 4328-4331.

[178] F. Toshimitsu, N. Nakashima, Nature Communications, 5 (2015).

[179] Y. Joo, G.J. Brady, M.J. Shea, M.B. Oviedo, C. Kanimozhi, S.K. Schmitt, B.M.

Wong, M.S. Arnold, P. Gopalan, ACS Nano, (2015).

[180] S.-H. Lee, D. Khim, Y. Xu, J. Kim, W.-T. Park, D.-Y. Kim, Y.-Y. Noh, Sci. Rep., 5 (2015).

[181] M.C. Gwinner, F. Jakubka, F. Gannott, H. Sirringhaus, J. Zaumseil, ACS

Nano, 6 (2012) 539-548.

[182] T.-S. Pui, H.G. Sudibya, X. Luan, Q. Zhang, F. Ye, Y. Huang, P. Chen, Advanced Materials, 22 (2010) 3199-3203. 
[183] M.B. Lerner, N. Kybert, R. Mendoza, R. Villechenon, M.A. Bonilla Lopez, A.T. Charlie Johnson, Applied Physics Letters, 102 (2013) 183113. 


\section{Authors Biographical Sketch}

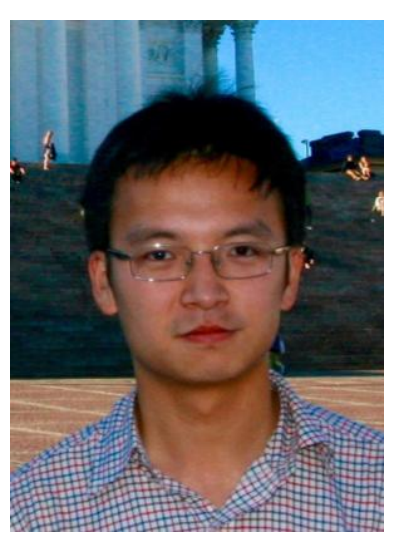

Huiliang (Evan) received his BEng/MEng degree in Materials Science from University of Oxford in 2010. He then finished his PhD degree at Materials Science and Engineering department at Stanford University in 2014 under guidance of Prof Zhenan Bao. His thesis project was on "Sorting of carbon nanotubes by conjugated polymers and their applications in flexible electronics". He is now a postdoctoral scholar in Prof Karl Deisseroth's group at Bioengineering Department of Stanford University. He is a recipient of Link Energy Foundation fellowship (2012 2014), MRS Gold Graduent Student Award (2014), AVS Graduate Student Award (2014), ACS Excellence in Graduat Polymer Research Award (2014) and Chinese Government Award For Outstanding Self-Financed Students Abroad (2014).

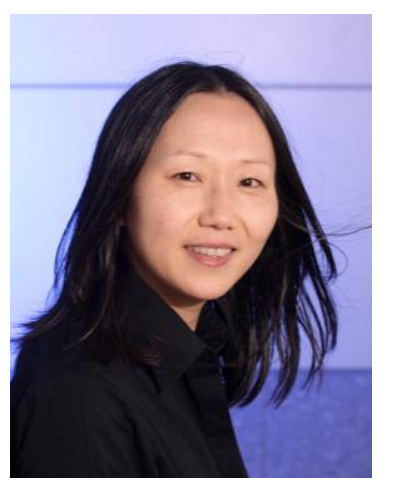

Zhenan Bao is a Professor of Chemical Engineering at Stanford University and,by courtesy, a Professor of Chemistry, Material Science, and Engineering. Prior to joining Stanford in 2004, she was a Distinguished Member of Technical Staff in Bell Labs, Lucent Technologies, from 1995 to 2004. She has over 300 refereed publications and over 40 US patents. She is a Fellow of the AAAS, ACS, MRS, SPIE, ACS PMSE, and ACS POLY. She served as a Board Memberfor the National Academy Board on Chemical Sciences and Technology and Board of Directors for the MRS. She is a recipient of the AIChE Andreas Acrivos Award for Professional Progress in Chemical Engineering (2014), ACS Polymer Division Carl S. Marvel Creative Polymer Chemistry Award (2013), ACS Author Cope Scholar Award (2011), Royal Society of Chemistry Beilby Medal and Prize (2009), IUPAC Creativity in Applied Polymer Science Prize (2008), American Chemical Society Team Inno-vation Award (2001), and R\&D 100 Award (2001). 
Graphical Abstract (for geview)swNT

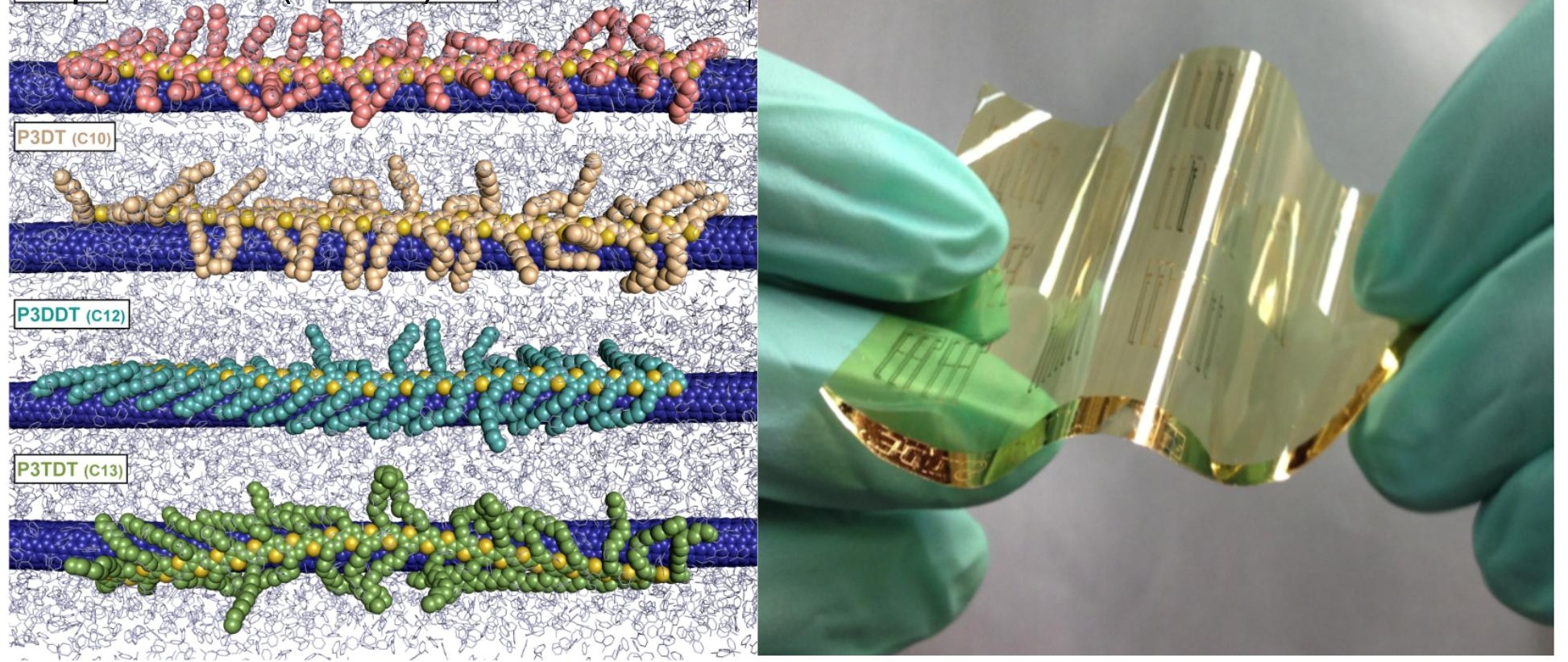

